Tálita Coffler Botti

Transporte de Sólidos em Escoamento Laminar

Dissertação apresentada como requisito parcial para obtenção do grau de Mestre pelo Programa de Pósgraduação em Engenharia Mecânica da PUC - Rio.

Orientador: Prof. Márcio da Silveira Carvalho

Rio de Janeiro Setembro de 2014 
Tálita Coffler Botti

\section{Transporte de Sólidos em Escoamento Laminar}

Dissertação apresentada como requisito parcial para obtenção do grau de Mestre pelo Programa de Pós-graduação em Engenharia Mecânica do Departamento de Engenharia Mecânica do Centro Técnico Científico da PUC - Rio. Aprovada pela Comissão Examinadora abaixo assinada.

Prof. Márcio da Silveira Carvalho

Orientador

Departamento de Engenharia Mecânica - PUC - Rio

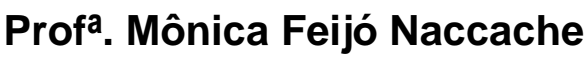

Departamento de Engenharia Mecânica - PUC - Rio

Dr. André Leibsohn Martins

Petrobras

Prof. José Eugenio Leal

Coordenador do Centro Técnico Científico - PUC - Rio

Rio de Janeiro, 05 de setembro de 2014. 
Todos os direitos reservados. É proibida a reprodução total ou parcial do trabalho sem autorização da universidade, da autora e do orientador.

\section{Tálita Coffler Botti}

Tálita Coffler Botti graduou-se em Engenharia de Petróleo pela Universidade Federal do Espírito Santo [2011].

Ficha catalográfica

Botti, Tálita Coffler

Transporte de Sólidos em Escoamento Laminar / Tálita Coffler Botti; orientador: Márcio da Silveira Carvalho. -2014.

71 f.: il. (color.) ; $30 \mathrm{~cm}$

Dissertação (mestrado) - Pontifícia Universidade Católica do Rio de Janeiro, Departamento de Engenharia Mecânica, 2014.

Inclui bibliografia.

1. Engenharia Mecânica - Teses. 2. Carreamento de partículas. 3. Ressuspensão viscosa. 4. Método de elementos finitos. 5. Perfuração. I Carvalho, Márcio da Silveira. II. Pontifícia Universidade Católica do Rio de Janeiro. Departamento de Engenharia Mecânica. III. Título. 
A Deus, que ilumina meu caminhar e à minha família, meu porto seguro. 


\section{Agradecimento}

Primeiramente a Deus, autor da minha vida e força na minha caminhada, sempre me ajudando a não desistir dos meus sonhos.

Aos meus pais e minha irmã pelo amor, carinho e encorajamento a buscar sempre mais.

À minha família, meu namorado e meus amigos, que mesmo distante, me apoiaram e me incentivaram a concluir esta etapa importante de minha vida.

Ao meu orientador Professor Márcio pelo incentivo, apoio e dedicação para a realização deste trabalho.

Aos colegas de pesquisa do Laboratório de Micro-Hidrodinâmica em Meios Porosos, amigos e professores da PUC-Rio.

A CAPES e a PUC-Rio pelos auxílios concedidos, sem os quais este trabalho não poderia ter sido realizado.

A Baker Hughes pelo incentivo e apoio financeiro à pesquisa.

A todos aqueles que neste período estiveram presentes e contribuíram de alguma forma na minha caminhada. 


\section{Resumo}

Botti, Tálita Coffler; Carvalho, Márcio da Silveira. Transporte de Sólidos em Escoamento Laminar. Rio de Janeiro, 2014. 71p. Dissertação de Mestrado - Departamento de Engenharia Mecânica, Pontifícia Universidade Católica do Rio de Janeiro.

Após a década de 80 tornou-se frequente a utilização de poços direcionais, tanto poços horizontais quanto os de longo alcance, nas operações de desenvolvimentos de campos petrolíferos, os quais permitiram grande avanço na exploração. Este cenário, porém, traz grandes desafios para operações de perfuração relacionadas à limpeza de poços. A limpeza de poços consiste na remoção dos cascalhos de dentro do anular do poço através da circulação do fluido de perfuração. Devido à inclinação do poço, os cascalhos sofrem a ação da gravidade sendo empurrados para o fundo do canal, já que possuem densidade maior que a da fase líquida, assim, transportados a uma velocidade menor que a velocidade do escoamento. Ao se depositarem no fundo do canal, formam um leito estacionário, obstruindo parte do anular e diminuindo a vazão, o que gera problemas, como por exemplo, redução da taxa de penetração, desgaste prematuro da broca, elevação do torque e arraste, aprisionamento da coluna, perda de circulação, dentre outros, podendo gerar a perda do poço. Desta forma, o perfeito entendimento do processo de sedimentação e transporte de partículas sólidas suspensas em fluido é fundamental para a otimização do processo de perfuração de poços. Este trabalho analisa o escoamento laminar bidimensional de suspensões de partículas sólidas devido a um gradiente de pressão entre duas placas paralelas, representando uma descrição simplificada do escoamento que ocorre em um anular de poço durante o processo de perfuração. O perfil do leito de partículas ao longo do canal e a relação vazão-diferença de pressão para diferentes condições de escoamento são determinados pela solução numérica das equações que descrevem o problema. A formulação matemática leva a um sistema acoplado de três equações diferenciais: conservação de massa e de quantidade de movimento e a equação de transporte, que engloba os efeitos de difusão de partículas devido à frequência de interação entre as partículas, ao gradiente de viscosidade e à diferença de densidade entre o líquido e as partículas. O sistema é 
resolvido pela técnica de Elementos Finitos, através do método de Galerkin. Os resultados obtidos serão de extrema importância no desenvolvimento de modelos mais precisos que descrevam o processo de transporte de sólidos em anulares de poços.

\section{Palavras-chave}

Carreamento de partículas; ressuspensão viscosa; método de elementos finitos; perfuração. 


\section{Abstract}

Botti, Tálita Coffler; Carvalho, Márcio da Silveira (Advisor). Solids Transport in Laminar Flow. Rio de Janeiro, 2014. 71p. MSc Dissertation Departamento de Engenharia Mecânica, Pontifícia Universidade Católica do Rio de Janeiro.

After the 80's, the use of directional wells, both horizontal and long range wells, became frequent in the development of oil fields, which allowed great progress in exploration. This scenario, however, brings great challenges to operations related to wellbore cleaning. Wellbore cleaning consists in the removal of cuttings from within the annular through the circulation of drilling fluid. Due to the inclination of the well, the cuttings undergo the action of gravity and more to the bottom of the channel, as they have higher density than the liquid phase. They may be transported with a speed less than the speed of the liquid flow. When deposited on the channel, the cuttings form a stationary bed, blocking part of the annular and decreasing the flow rate that causes problems, such as reducing the rate of penetration, premature wear of the bit, high torque and drag, trapping column, loss of circulation and others, which may cause the loss of the well. Therefore, the fundamental understanding of particle sedimentation and transport in a suspending flowing liquid is necessary for drilling operation design and optimization. This research studies the laminar two-dimensional flow of solid particles suspended in a liquid due to a pressure gradient between two parallel plates, representing a simplified description of the flow that occurs in an annular during the drilling process. The profile of the particle bed along the channel and the flow rate pressure difference relationship for different flow conditions are determined. The mathematical formulation leads to a coupled system of three differential equations: mass and momentum conservation and transport equation, which includes the effects of particle diffusion due to the frequency of interaction between the particles, the gradient of viscosity and the difference density between the liquid and the particles. The system is solved by the finite element method Galerkin. The results will be of extreme importance in the development of more accurate models that describe the solids transport process in annular space. 


\section{Keywords}

Particle transport; viscous resuspension; finite element method; drilling. 


\section{Sumário}

1 Introdução 18

$\begin{array}{lr}\text { 1.1. Revisão Bibliográfica } & 19\end{array}$

$\begin{array}{ll}\text { 1.2. Objetivo } & 24\end{array}$

2 Formulação Matemática $\quad 25$

2.1. Considerações Gerais 25

2.2. Equações Governantes 27

2.3. Condições de Contorno 35

2.4. Método de Solução 35

2.4.1. Solução através do método de Galerkin 36

2.4.2. Solução do sistema de equações lineares pelo método de $\begin{array}{ll}\text { Newton } & 38\end{array}$

3 Resultados $\quad 40$

3.1. Efeito do comprimento do canal 43

3.2. Efeito da variação da densidade das partículas 47

3.3. Efeito da variação das constantes de proporcionalidade $\mathrm{K}_{\mathrm{c}}$ e $\mathrm{K}_{\mu} \quad 54$

3.4. Efeito da Variação da Pressão 57

4 Comentários Finais/Sugestões $\quad 67$

5 Referência Bibliográfica $\quad 69$ 


\section{Lista de figuras}

Figura 1-1- (a) Esquema do processo de carreamento de cascalhos (b) anular com leito de cascalhos (Fonte: Costa e Fontoura, 2005).

Figura 2-1 - Esquema que representa a simplificação da geometria do problema.

Figura 2-2 - Esquema de fluxo.

Figura 2-3 - Viscosidade da suspensão normalizada (Fonte: Silva, 2013).

Figura 2-4 - Colisões irreversíveis entre dois corpos com (a) taxa de cisalhamento variável, (b) viscosidade constante e (c) variação espacial da viscosidade (Fonte: Phillips et al. 1992).

Figura 2-5 - Condições de contorno utilizadas no problema.

Figura 3-1 - Perfis de concentração ao longo do canal para o teste

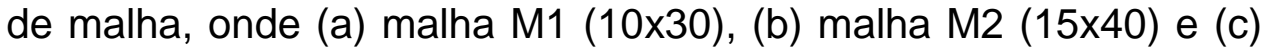
malha M3 (20x50).

Figura 3-2 - Perfis de concentração na saída do canal para os três tamanhos de malha testados.

Figura 3-3 - Perfis de concentração ao longo do canal para os comprimentos de: (a) 2 metros e (b) 4 metros.

Figura 3-4 - Perfil de concentração para os dois casos no ponto em $x=2$ metros.

Figura 3-5 - Perfis de concentração dos dois canais em $\mathrm{x}=10 \mathrm{~m}$.

Figura 3-6 - Perfis de velocidade dos dois canais em $x=10 \mathrm{~m}$.

Figura 3-7 - Perfil de concentração ao longo do canal para os casos com s igual a: (a) $8,76.10^{-6}$; (b) $2,62.10^{-5}$ e (c) $4,88.10^{-5}$.

Figura 3-8 - Perfis de concentração na saída do canal para os casos em que a densidade das partículas é alterada.

Figura 3-9 - Perfis de velocidade na saída do canal para os casos em que a densidade das partículas é alterada.

Figura 3-10 - Perfis de concentração ao longo do canal para os casos com $s$ igual a: (a) $2,79 \cdot 10^{-5}$ (b) $5,58 \cdot 10^{-5}$ e (c) $8,37.10^{-5}$. 
Figura 3-11 - Iso-linha de $\varnothing=0,5$, representando a superfície do leito de partículas ao longo do canal.

Figura 3-12 - Perfis de concentração na saída do canal para os casos variou-se a densidade das partículas, consequentemente $s$.

Figura 3-13 - Perfis de velocidade na saída do canal para os casos variou-se a densidade das partículas, consequentemente $s$.

Figura 3-14 - Perfis de concentração na saída do canal para os casos em que o $\mathrm{K}_{\mathrm{c}}$ foi variado.

Figura 3-15 - Perfis de concentração na saída do canal para os casos em que o $\mathrm{K}_{\mu}$ foi variado.

Figura 3-16 - Perfis de concentração para os casos em que a razão $\lambda$ foi mantida constante.

Figura 3-17 - Perfis de concentração ao longo do canal para os casos cujo $\Delta P^{\star}$ vale: (a) 282,84, (b) 308,22, (c) 331,66, (d) 353,55, (e) 393,70 e (f) 412,31 .

Figura 3-18 - Perfis que mostram a evolução da formação do leito de sedimentos $(\varnothing \geq 0,5)$ ao longo do canal.

Figura 3-19 - Perfis de velocidade na saída do canal para os casos em que $\Delta P^{*}$ era variado.

Figura 3-20 - Perfis de concentração na saída do canal para os casos em que $\Delta P^{*}$ era variado.

Figura 3-21 - Perfis de concentração ao longo do canal para um $\Delta \rho=25,3 \mathrm{~kg} / \mathrm{m} 3$ e um $\Delta P^{*}$ diferente para os dois casos, sendo (a) 1303,84 e (b) 1974,84 .

Figura 3-22 - Perfis de concentração e velocidade, para $\Delta \rho=25,3 \mathrm{~kg} / \mathrm{m} 3$ e $\Delta P^{*}=1303,84$.

Figura 3-23 - Perfis de concentração na saída do canal para os diferentes valores de $\Delta P^{*}$ e $s$.

Figura 3-24 - Perfis de velocidade na saída do canal para os diferentes valores de $\Delta P^{\star}$ e $s$.

Figura 3-25 - Diagrama representando a relação entre a altura do leito e o parâmetro adimensional $s$. 


\section{Lista de tabelas}

Tabela 2-1 - Comparação entre os valores de alguns adimensionais para o caso real e a dissertação.

Tabela 2-2 - Graus de Liberdade de cada elemento. 38

Tabela 3-1 - Dados utilizados para o teste de malhas.

Tabela 3-2 - Dados utilizados para as simulações que comparam os diferentes comprimentos do canal.

Tabela 3-3 - Dados utilizados para as simulações que comparam os diferentes comprimentos do canal.

Tabela 3-4 - Dados do primeiro conjunto de simulações para diferentes valores de $\Delta \rho$.

Tabela 3-5 - Dados do segundo conjunto de simulações para diferentes valores de $\Delta \rho$.

Tabela 3-6 - Dados das simulações para diferentes valores de $\mathrm{K}_{\mathrm{c}}$.

Tabela 3-7 - Dados das simulações para diferentes valores de $\mathrm{K}_{\mu}$.

Tabela 3-8 - Dados das simulações que testaram a limitação numérica do programa.

Tabela 3-9 - Dados das simulações que avaliam a variação do $\Delta \boldsymbol{P}^{\star}$.

Tabela 3-10 - Dados das simulações para variados valores de $\Delta \boldsymbol{P}$ e $\Delta \rho$. 


\section{Lista de símbolos}

a

$\vec{g}$

$\overline{\bar{G}}$

$\mathrm{H}$

$\overline{\bar{I}}$

$\overline{\bar{J}}$

$J_{T}$

$K_{c}$

$K_{\mu}$

L

$\vec{n}$

$N_{t}$

$N_{c}$

$N_{\mu}$

$N_{s}$

$\mathrm{p}$

$P_{e}$

$P_{1}$

$P_{2}$

Q

$Q^{*}$ raio das partículas

vetor aceleração da gravidade

gradiente da velocidade interpolada

altura do canal

tensor identidade

matriz Jacobiana do método iterativo de Newton

determinante da Jacobiana

coeficiente de migração devido ao gradiente de taxa de cisalhamento

coeficiente de migração devido ao gradiente de viscosidade

comprimento do canal

vetor normal a parede

fluxo de migração total de partículas

fluxo de migração de partículas devido ao gradiente de taxa de cisalhamento

fluxo de migração de partículas devido ao gradiente de viscosidade

fluxo de migração de partículas devido a diferença de densidade entre as partículas sólidas e a fase líquida

pressão

número de Peclet Hidrodinâmico

pressão na entrada do canal

pressão na saída do canal

vazão do escoamento

vazão adimensional 


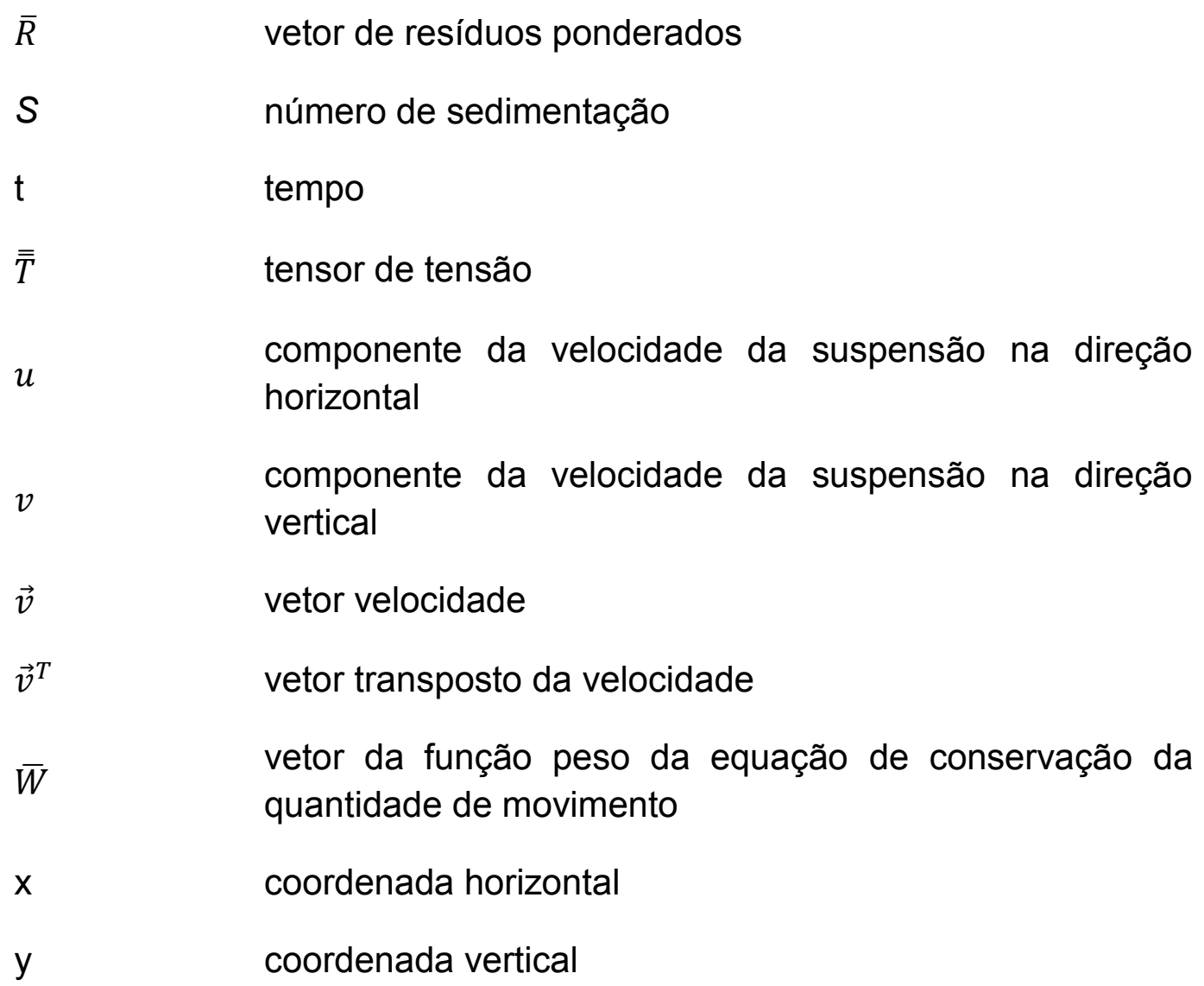




\section{Símbolos Gregos}

$\dot{\gamma}$

$\overline{\dot{\gamma}}$

$\Gamma$

$\bar{\Gamma}$

$\Delta \rho$

$\Delta P$

$\Delta P^{*}$

$\lambda$

$\mu(\varnothing)$

$\mu_{r}$

$\mu_{l}$

$\bar{\mu}$

$\bar{\xi}$

$\xi$

$\pi$

$\rho$

$\overline{\bar{\tau}}$

$\varphi$

$\varphi_{j}$

$\emptyset$

$\emptyset m$

$\emptyset o$ taxa de deformação

tensor taxa de deformação

limite do domínio físico

limite do domínio de referência

diferença de densidade entre as partículas e a fase líquida

diferencial de pressão imposta

Diferencial de pressão adimensional

razão de difusividade

viscosidade da suspensão de partículas

viscosidade efetiva

viscosidade da fase líquida

viscosidade da suspensão considerando ø igual ao $\emptyset_{m}$

vetor posição do domínio de referência

coordenada horizontal do domínio de referência

número pi

densidade

tensor de tensão viscoso

função peso para a equação de transporte

função base polinomial biquadrática Lagrangiana

concentração de partículas

concentração média de partículas na entrada

concentração de partículas para o grau de empacotamento máximo 
$\psi_{j}$

$\Omega$

$\bar{\Omega}$

função peso para a equação da continuidade

função base descontinua linear

função peso para a equação do gradiente da velocidade interpolada

função base polinomial bilinear Lagrangeana

domínio físico

domínio de referência 


\section{Introdução}

Durante a operação de perfuração de poços de petróleo são gerados sedimentos provenientes do corte da formação pela broca, como ilustra a Figura 1-1(a). Esses sedimentos, também conhecidos como cascalhos, são removidos de dentro do poço pelo espaço anular pelo escoamento da lama de perfuração. Normalmente, a limpeza do poço consiste na circulação do fluido de perfuração que entra no poço através da coluna de perfuração e sai pelos jatos da broca atingindo o espaço anular, espaço formado entre coluna e a parede do poço, onde se encontram os cascalhos.

A remoção destes cascalhos nem sempre é realizada com sucesso, sendo fortemente influenciada pela geometria do sistema como, por exemplo, nos poços horizontais ou de grande inclinação. Nesses casos, a ação da gravidade pode levar a formação de um leito de partículas, já que os sólidos, por serem mais densos que o fluido, tendem a se depositar mais facilmente no fundo do canal (Figura 1-1 (b)). Como consequência disto surgem alguns problemas, tais como: redução da taxa de penetração, perda de circulação, elevação do torque e arraste, obstrução do anular, prisão coluna, podendo até mesmo provocar a perda do poço (Costa e Fontoura, 2005).

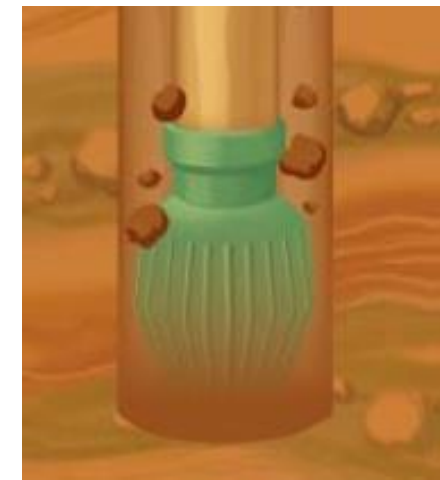

(a)

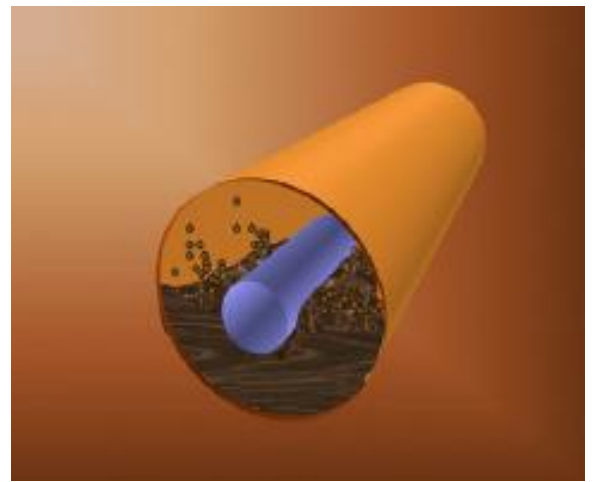

(b)

Figura 1-1- (a) Esquema do processo de carreamento de cascalhos (b) anular com leito de cascalhos (Fonte: Costa e Fontoura, 2005). 
Poços direcionais tornaram-se frequentes nas operações de desenvolvimento de campos de petróleo nas décadas de 80 e 90. Hoje em dia, a grande maioria dos poços de desenvolvimento dos campos é direcional, incluindo poços horizontais e de longo alcance. O avanço dessa tecnologia permitiu que esses poços alcançassem objetivos cada vez mais distantes da sonda, além de serem usados como método de aumento de produtividade, já que expõe uma maior extensão do reservatório a produção.

Como os custos operacionais da perfuração tanto de um poço exploratório, quanto de um poço de desenvolvimento são altos, é necessário cada vez mais estudar os problemas que ocorrem durante a perfuração, a fim de minimizá-los, buscando-se modelos mais precisos para descrever todo o processo.

O problema do transporte de sólidos não ocorre apenas para o cenário da indústria petrolífera, portanto na literatura é possível encontrar várias linhas de pesquisas que se desenvolveram na busca da solução deste problema.

Nosso estudo estará voltando para o fenômeno de ressuspensão viscosa, primeiramente observado por Gadala-Maria (1979), seguido por diversos autores. Este fenômeno é o processo pelo qual, na presença de um escoamento cisalhante, uma camada de partículas rígidas e mais densas que o fluido, inicialmente em repouso, é novamente colocada em movimento, sendo arrastada pelo fluido.

\section{1. \\ Revisão Bibliográfica}

O objetivo das pesquisas neste assunto é determinar a distribuição das partículas dentro do canal por onde ocorre o escoamento e a mudança no comportamento do fluxo em resposta a alterações em determinados parâmetros. Sabe-se que a adição de partículas em um fluido Newtoniano modifica o comportamento do escoamento, alterando os campos de velocidade e pressão (Silva, 2013). A migração e a distribuição das partículas são definidas pela geometria e parâmetros do escoamento e pelas condições de fronteira do problema.

Como mencionado anteriormente, muitas pesquisas têm se direcionado para o fluxo de ressuspensão viscosa. Devido à alta complexidade do problema, um grande número de publicações, tanto no aspecto analítico quanto 
experimental, pode ser encontrada na literatura. Nesta seção, serão destacadas algumas publicações.

Ressuspensão viscosa é um processo pelo qual, na presença de um escoamento de cisalhamento, uma camada de partículas inerte é arrastada pelo escoamento de fluido, mesmo sob condições de Reynolds muito pequeno. Este fenômeno foi estudado tanto experimental quanto teoricamente por vários autores, como por exemplo: Gadala Maria (1979), Leighton e Acrivos (1986), Schanflinger et al. (1990), Chapman e Leighton (1991), Acrivos et al (1993) entre outros, que serão citados posteriormente.

Leighton e Acrivos (1986) destacaram que este fenômeno foi primeiramente observado por Gadala-Maria em 1979, quando esses autores realizaram medições de propriedades reológicas de suspensão de partículas de carvão em um fluido Newtoniano usando um dispositivo de placas paralelas. Observando que, quando essa suspensão era cisalhada a baixas taxas de cisalhamento depois de ter ficado de repouso por um tempo, o valor inicial da viscosidade era significativamente menor do que a medida anteriormente ao repouso. Eles concluíram que isso teria acontecido, pois uma parte das partículas havia se depositado, formando um leito, que posteriormente, quando novamente cisalhado, teria sido ressuspendido fazendo com que a viscosidade atingisse o mesmo valor inicial.

Com o objetivo de analisar a causa desses resultados observados por Gadala-Maria, Leighton e Acrivos (1986) repetiram os experimentos sob uma ampla faixa de parâmetros e mostraram que este fenômeno pode ser explicado em termos do processo de difusão por cisalhamento induzido, diferente da difusão Browniana convencional (que é negligenciada devido ao tamanho das partículas utilizadas). Eles desenvolveram uma relação para o aumento da altura do leito de sedimentação, que é resultado de uma tensão cisalhante aplicada na superfície do sedimento. Desta relação e de coeficientes de difusão estimados na literatura (Leighton e Acrivos, 1987a) eles determinaram condições sobre a qual uma camada de partículas poderia ser ressuspendida.

Em um estudo similar, Schaflinger et al.(1990) investigaram teoricamente a ressuspensão viscosa para dois casos diferentes, um o escoamento de HagenPoiseuille bidimensional e o outro o fluxo gravitacional de filme ao longo de um plano inclinado. Nos dois casos, a tensão de cisalhamento não é constante. Para o fluxo de Hagen-Poiseuille existe um plano no canal onde ela é nula, impondo um limite superior para a altura da camada ressuspendida. Além disso, para o filme de fluxo sob a ação da gravidade, um valor crítico é determinado para a 
concentração volumétrica de sólidos na alimentação, acima do qual as partículas se assentam e formam uma camada de sedimentos na placa que cresce continuamente em função do tempo. Este estudo foi baseado no modelo desenvolvido por Leighton e Acrivos 1986, o qual o fluxo de partículas descendentes devido à gravidade é balanceado pelo fluxo difusivo causado pelo movimento aleatório das partículas através do cisalhamento induzido. O modelo também despreza o movimento Browniano das partículas, devido ao tamanho das mesmas.

Phillips et al. (1992) propuseram uma formulação matemática para descrever o campo de concentração de partículas e de velocidade em suspensões monomodais concentradas, consistindo de duas partes: equação da conservação da quantidade de movimento considerando o fluido Newtoniano com viscosidade dependente da fração volumétrica de partículas local, e uma equação de difusão que leva em consideração a migração de partículas por gradiente de taxa de cisalhamento e viscosidade. Este modelo é também chamado de modelo de fluxo difusivo. Nesse tipo de fluxo, em geral, se observa a migração de partículas das regiões de altas taxas de cisalhamento para regiões com baixas taxas de cisalhamento. Essa migração ocorre para números de Reynolds suficientemente baixos $\left(\sim 10^{-4}\right)$, podendo-se desprezar os efeitos de inércia. Esses autores consideraram duas configurações diferentes em seus experimentos, o fluxo de Couette entre cilindros concêntricos em rotação e o fluxo de Poiseuielle através de um tubo cilíndrico.

Também em 1992, Zhang et al realizaram uma análise da estabilidade linear do escoamento de ressuspensão viscosa que se desenvolve de uma alimentação de partículas bem misturadas ao longo de um canal bidimensional, baseada no modelo de dois fluidos em que a não uniformidade da distribuição da concentração de partículas dentro da camada suspendida é ignorada. Este fluxo foi estudado anteriormente por Schanflinger et al, 1990, onde mostraram que a extensão da ressuspensão era governada pelo número de Shields modificado,

$$
k=\frac{9}{16} \frac{\mu_{l} Q}{B^{3} g\left(\rho_{2}-\rho_{l}\right)}
$$

Onde $\mu_{l}$ é a viscosidade do líquido, $Q$ é a vazão de fluxo, $B$ é a metade da altura do canal, $g$ é a gravidade e $\rho_{2}$ e $\rho_{l}$ são as densidade das partículas e do líquido, respectivamente. 
Zhang et al verificaram que o fluxo de ressuspensão é convectivamente instável e que as maiores instabilidades ocorrem para moderados números de Reynolds. Mostraram também que a redução da concentração de partículas na alimentação do canal e/ou um incremento na razão de densidade relativa das partículas sólidas no fluido de suspensão aumentará a instabilidade do modo interfacial.

Em 1993, Acrivos realizou estudos experimentais da ressuspensão viscosa com um dispositivo de Couette. A medida da altura do leito encontrado por eles esteve de acordo com o modelo teórico apresentado por Leighton e Acrivos em 1986, no qual, o fluxo de partículas descendente sob o efeito da gravidade é balanceado pelo fluxo de partículas ascendente devido ao efeito da difusão por gradiente de taxa de cisalhamento.

No ano de 1994, em conjunto com Zhang, Acrivos investigou teoricamente a ressuspensão viscosa de partículas pesadas, num fluxo laminar totalmente desenvolvido em um tubo horizontal através do modelo estendido de Phillips para casos nos quais todas as três componentes da velocidade eram diferentes de zero devido à existência de movimento secundário dentro da seção transversal do tubo. Eles aplicaram o método de elementos finitos de Galerkin para resolver o sistema de equações diferenciais. A velocidade prevista teoricamente e os perfis de concentração encontrados concordaram qualitativamente muito bem com resultados de outros autores. Eles observaram que, na maioria dos casos, era formada devido à ação da gravidade uma região sem concentração de partículas no topo do tubo, que diminuía à medida que se aumentava a vazão ou a concentração de entrada.

Miskin (1996a,1996b) também realizou pesquisas sobre migração de partículas por cisalhamento induzido em um canal retangular inclinado e utilizou como base a teoria de Leighton e Acrivos (1986) e Schanflinger et al (1990). Primeiramente estudou a sedimentação da suspensão viscosa de partículas apenas sob a ação da força da gravidade, sem fluxo cruzado. Depois adicionou um fluxo de pressão na direção perpendicular ao fluxo original, um fluxo transversal. Ele resolveu numericamente as equações de conservação de massa, quantidade de movimento e concentração para uma ampla variedade de condições operacionais, sendo apresentada a concentração de partículas inicial, os perfis de velocidade e de concentração para vários ângulos de inclinação do canal. Deve ser notado que, nos trabalhos anteriores (Leighton e Acrivos, 1986), que lidam com difusão induzida por cisalhamento, se limitavam a fluxos unidirecionais em que o coeficiente de difusão é proporcional à taxa de 
cisalhamento local ou a tensão de cisalhamento. Embora a generalização deste resultado para escoamento bi ou tridimensionais não seja evidente e deve ser comprovada através de estudos experimentais, Miskin presumiu, por simplicidade, que o coeficiente de difusão induzida por cisalhamento é proporcional à taxa de cisalhamento local absoluto.

Em um dos seus trabalhos, ele observou que quando a suspensão entra no canal com um perfil de velocidade uniforme, quase que instantaneamente ele se torna parabólico. Além de que os efeitos da sedimentação das partículas são mais dominantes na região de entrada e mais a jusante ele é balanceado pela difusão de partículas por cisalhamento induzido, que se torna mais importante. Mostrou também que o fluxo de suspensão depende criticamente da escolha dos parâmetros usados, tais como a razão do diâmetro das partículas com a altura do canal.

Lalli e Mascio (1997) propuseram um modelo numérico que foi uma versão simplificada do modelo proposto por Rai e Moin (1991), baseado nos estudos de Leighton e Acrivos (1987b), para a simulação de escoamento de suspensão de partículas baseado num modelo contínuo, no qual os efeitos das partículas são levados em conta em termos de uma viscosidade efetiva. A equação da fase dispersa é baseada nos efeitos de sedimentação e difusão por cisalhamento induzido. Ele considerou seu trabalho sendo o primeiro passo para o desenvolvimento de um modelo geral para a simulação da interação entre ondas ou correntes e sedimentos. Ou seja, o trabalho proposto permite o estudo do transporte de sedimentos e a evolução da forma do leito sem a necessidade de um sistema de coordenadas curvilíneas. Assim, tanto a região de fluido limpo, a região de suspensão quanto a região do leito sedimentado são estudados como um modelo único com uma viscosidade efetiva própria. Os resultados foram obtidos para o fluxo bidimensional de Bingham, pelo método de diferenças finitas.

Os trabalhos teóricos apresentados na literatura consideram o escoamento desenvolvido. O objetivo das análises é determinar a altura do leito e a relação vazão - diferença de pressão em função das condições do escoamento e propriedades do fluido e das partículas sólidas.

A formação e crescimento do leito de partículas não é normalmente estudado, pois a complexidade do problema aumenta consideravelmente. 


\section{2.}

\section{Objetivo}

O presente trabalho tem como objetivo estudar o escoamento de suspensões de partículas sólidas devido a um gradiente de pressão entre duas placas paralelas. Este escoamento representa uma descrição simplificada do escoamento que ocorre em um anular de poço durante o processo de perfuração.

O estudo irá permitir a determinação do perfil do leito de partículas, isto é a variação da altura do leito ao longo do canal; e a relação vazão-diferença de pressão para diferentes condições de escoamento: vazão ou diferença de pressão imposta, diferença de densidade entre as partículas sólidas e a fase líquida e coeficientes de difusão dos mecanismos de migração de partículas sólidas.

Os resultados obtidos neste trabalho serão de extrema importância no desenvolvimento de modelos mais precisos que descrevam o processo de transporte de sólidos em anulares de poços. 


\section{2 \\ Formulação Matemática}

Ao longo dos anos, pesquisadores têm buscado descrever o problema do transporte de sólidos de forma mais detalhada e precisa possível, isto tanto para aplicação na indústria do petróleo quanto para outras áreas. Neste capítulo, o principal objetivo será apresentar as hipóteses feitas nesta análise para o estudo do escoamento laminar de suspensões de partículas entre placas, apresentar a formulação matemática incluindo o transporte de sólidos devido ao gradiente de taxa de cisalhamento, gradiente de viscosidade e sedimentação.

A suspensão de partículas é considerada um meio contínuo. O fluxo é assumido como laminar e governado pelas equações de conservação de massa e de quantidade de movimento, além da equação que descreve o transporte de partículas sólidas no meio líquido, uma equação difusão-convecção, que nos permitirá obter a distribuição da concentração dessas partículas. As soluções são em regime permanente e não será analisado o regime transiente neste estudo.

\section{1. \\ Considerações Gerais}

No cenário da indústria de petróleo, o escoamento de suspensões sólidas em um anular de poço é um problema complexo, pois envolve uma geometria tridimensional em coordenadas cilíndricas e o escoamento de um fluido complexo. Para simplificar o problema, vamos considerar o escoamento como bidimensional entre placas paralelas. Apesar da diferença geométrica, este escoamento apresenta todos os importantes fenômenos físicos do escoamento em um anular, como mostra a Figura 2-1.

O problema estudado, apresentado na Figura 2-2, representa o escoamento devido a uma diferença de pressão entre duas placas paralelas. Considera-se que na entrada a concentração de partículas é uniforme e o perfil de velocidade, parabólico. $O$ canal possui comprimento $L$ e altura $H$. 
O objetivo é calcular o campo de concentração de partículas e velocidade no domínio do escoamento, além de determinar a altura do leito depositado no fundo do canal em função das variáveis do problema.

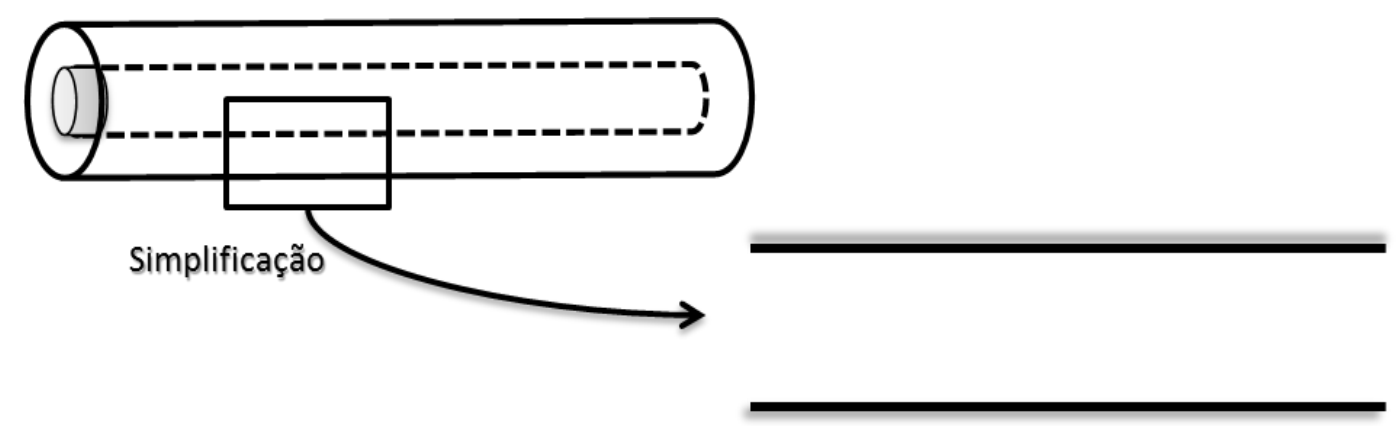

Figura 2-1 - Esquema que representa a simplificação da geometria do problema.

$\mathrm{Na}$ região de entrada do canal (Figura 2-2) temos uma alimentação de partículas com valor constante, $\emptyset_{m}$. Após estas partículas serem colocadas em fluxo observam-se duas regiões distintas: uma na base do canal, onde estará ocorrendo uma deposição maior de partículas, o que fará com que a viscosidade dessa suspensão nesta região seja tão alta que a velocidade tende a zero, isto é, leito estagnado; a outra região segue até o topo do canal, onde as partículas estão sendo carreadas pelo fluido e a sua distribuição estará variando ao longo dessa região. Nesta última região, ainda poderá ser observado, dependendo das condições, no topo do canal o fluxo de fluido limpo, sem nenhuma partícula.

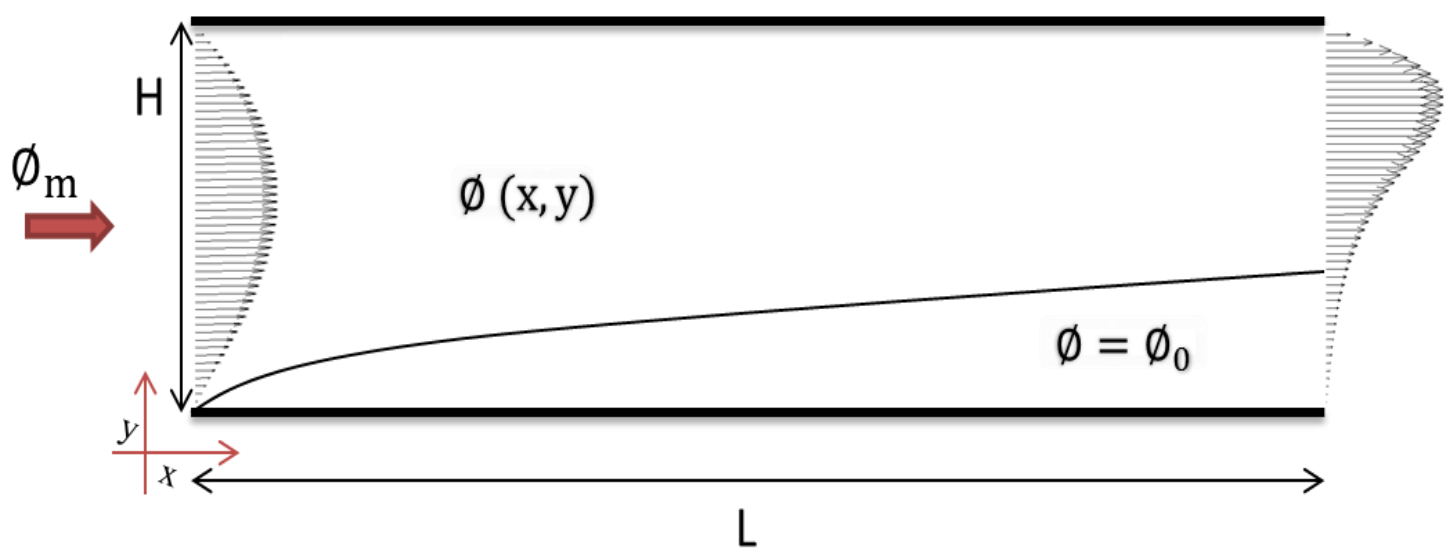

Figura 2-2 - Esquema de fluxo. 
Algumas hipóteses são adotadas para simplificar o problema:

i. Fluxo em regime permanente

ii. Fase líquida incompressível

iii. Fluxo bidimensional

iv. Efeitos de inércia negligenciados

v. Não deslizamento na parede

Neste estudo não haverá transferência de calor entre as paredes do canal do canal com o fluxo. A deposição e a ressuspensão das partículas não tem efeito na temperatura do fluxo e nas paredes do canal.

Assim como Leighton e Acrivos (1986), iremos desprezar os efeitos de difusão Browniana, já que o tamanho das partículas são considerados grande suficientes $(d>1 \mu m)$.

\section{2.}

\section{Equações Governantes}

Aqui são apresentadas as equações derivadas dos princípios de conservação de massa e quantidade de movimento linear (Panton, 2005). A suspensão (parte fluida e as partículas) é considerada como um meio continuo, sendo assim as equações de conservação de massa e momento linear são:

- Equação da Continuidade (conservação de massa):

$$
\frac{\partial \rho}{\partial t}=-(\nabla \cdot \rho \vec{v})
$$

- Equação de Conservação da quantidade de movimento linear:

$$
\rho \frac{D \vec{v}}{D t}=\nabla \cdot \overline{\bar{T}}+\rho \vec{g}
$$

Assumindo-se que ambas as fases líquidas e sólidas são incompressíveis e utilizando as demais hipóteses, as equações acima podem ser simplificadas:

$$
\nabla \cdot \vec{v}=0
$$




$$
\nabla \cdot \overline{\bar{T}}=0
$$

O tensor de tensão, $\overline{\bar{T}}$, pode ser decomposto em termos da pressão e do tensor de tensão devido ao movimento do fluido:

$$
\overline{\bar{T}}=-p \overline{\bar{I}}+\overline{\bar{\tau}},
$$

onde $\overline{\bar{I}}$ é o tensor identidade.

A suspensão será modelada como um fluido Newtoniano, porém com a viscosidade variando com a concentração de partículas local. Portanto, o tensor de tensão viscoso é dado por:

$$
\overline{\bar{\tau}}=\mu(\varnothing) \overline{\bar{\gamma}}
$$

onde $\overline{\bar{\gamma}}$ é o tensor taxa de deformação e é dado por:

$$
\overline{\bar{\gamma}}=\nabla \vec{v}+\nabla \vec{v}^{T}
$$

$\mu(\varnothing)$ é a viscosidade da suspensão, que é função da concentração de partículas. $\mathrm{Na}$ literatura existem duas principais equações que descrevem a viscosidade efetiva, propostas por:

- Krieger (1972):

$$
\mu_{r}=\mu(\varnothing) / \mu_{l}=\left(1-\frac{\emptyset}{\emptyset_{0}}\right)^{-2,67 . \emptyset_{0}}
$$

- Leighton e Acrivos (1986)

$$
\mu_{r}=\left(1+\frac{1,5 \emptyset}{1-\emptyset / \emptyset_{0}}\right)^{2}
$$


Onde $\mu_{r}$ é a viscosidade relativa da suspensão, $\mu_{l}$ é a viscosidade do líquido e $\emptyset_{0}$ é a fração volumétrica de empacotamento máximo. Neste estudo será utilizada a equação proposta por Krieger (1972) e $\emptyset_{0}=0,68$, portanto:

$$
\mu_{r}=\left(1-\frac{\emptyset}{\emptyset_{0}}\right)^{-1,82}
$$

Esses modelos que levam em consideração a fração máxima de empacotamento, $\emptyset_{0}$, possuem um ponto de singularidade quando esse valor é atingido, como mostrado na Figura 2-3. $O$ valor de $\emptyset_{0}$ depende da forma e da interação das partículas e para esferas monodispersas seu valor se encontra entre 0,58 e 0,72 .

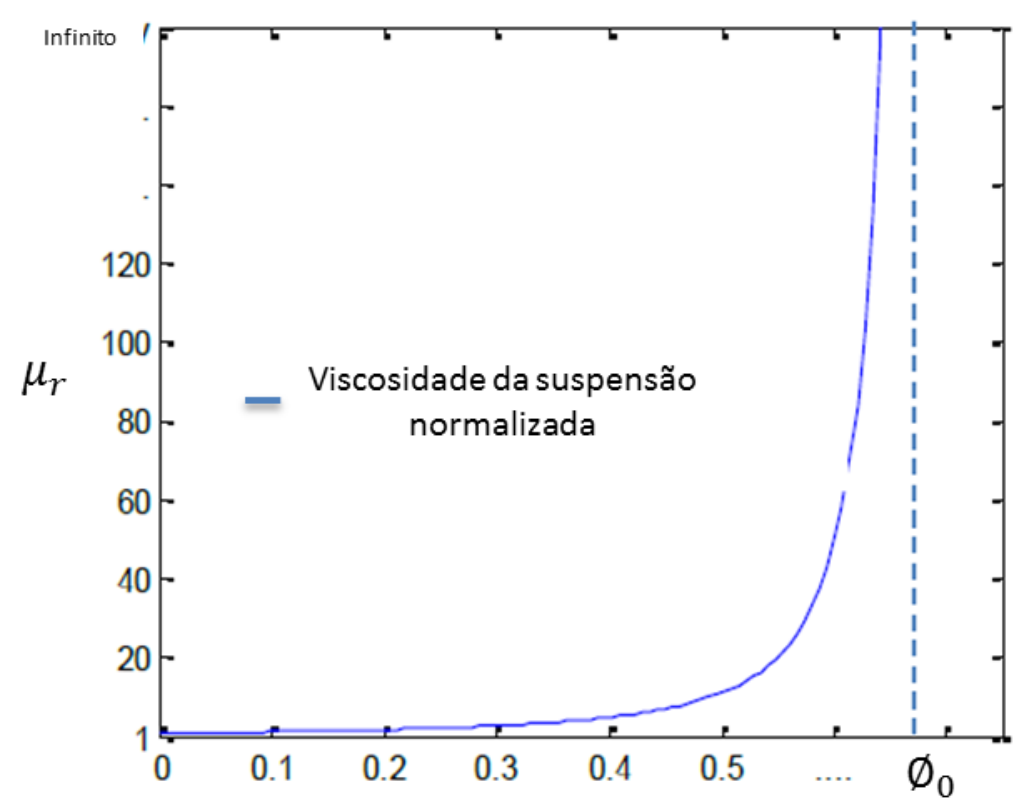

Figura 2-3 - Viscosidade da suspensão normalizada (Fonte: Silva, 2013).

Observa-se pelo gráfico acima, que para concentrações maiores que 0,5 a viscosidade da suspensão começa a subir, levando rapidamente esse valor ao infinito.

Como mencionado anteriormente, o sistema será composto por três equações, portanto a última equação a ser detalhada é a Equação de Transporte de partículas, baseada na conservação de massa de partículas sólidas, dada por: 


$$
\vec{v} \cdot \nabla \emptyset=\nabla \cdot N_{t} .
$$

$N_{t}$ representa o fluxo total de partículas devido aos diferentes mecanismos de migração das partículas. Dentro do fluxo de partículas ocorrem muitos tipos de interações potencialmente importantes, no entanto, detalhar esse problema com todas as variáveis existentes seria inviável no campo da simulação numérica. Assim é proposta uma abordagem simplificada que tenta captar apenas os efeitos mais importantes.

Phillips et al. (1992) destaca que as interações (influência de uma partícula sobre o movimento de outra partícula vizinha) entre duas partículas esféricas e lisas em suspensão em um escoamento são reversíveis, portanto cada partícula pode voltar a sua linha de corrente original após a colisão. Porém, se esta migração ocorrer de regiões de alto cisalhamento para regiões de baixo cisalhamento existirá uma componente de irreversibilidade na interação que não permitirá que as partículas retornem para as suas linhas de corrente originais.

Neste trabalho, nos assumiremos que a migração de partículas ocorre através de três mecanismos de interação, são eles:

\section{a. Efeito da variação espacial da frequência de interação} (gradiente da taxa de cisalhamento induz a migração): este mecanismo ocorre devido à frequência de colisões que as partículas sofrem. As partículas colidem entre si, devido à diferença de velocidade relativa das linhas de corrente adjacentes. A frequência de colisão é proporcional a taxa de cisalhamento, o que resulta em maiores frequências de colisão entre as partículas em regiões com maiores taxas de cisalhamento. Desta forma, o movimento de migração das partículas é das regiões de alto para baixo cisalhamento, ou seja, de regiões de alta frequência de colisões para regiões de baixa, como ilustrado na Figura 2-4 (a).

A equação constitutiva resultante para o fluxo de partículas em função da variação espacial da frequência de interação proposta por Phillips et al (1992) é:

$$
N_{c}=-K_{c} a^{2}\left(\emptyset^{2} \nabla \dot{\gamma}+\emptyset \dot{\gamma} \nabla \emptyset\right)
$$


onde $a$ é o raio da partícula e $K_{c}$ é uma constante de proporcionalidade ajustada através de dados experimentais.

(a)

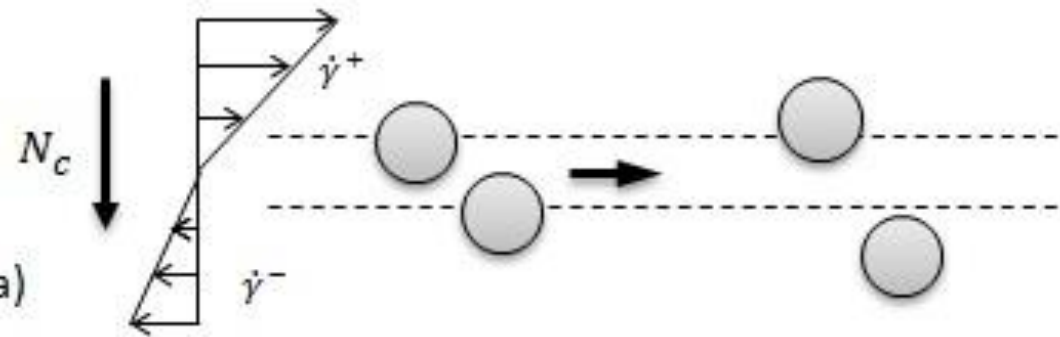

(b)
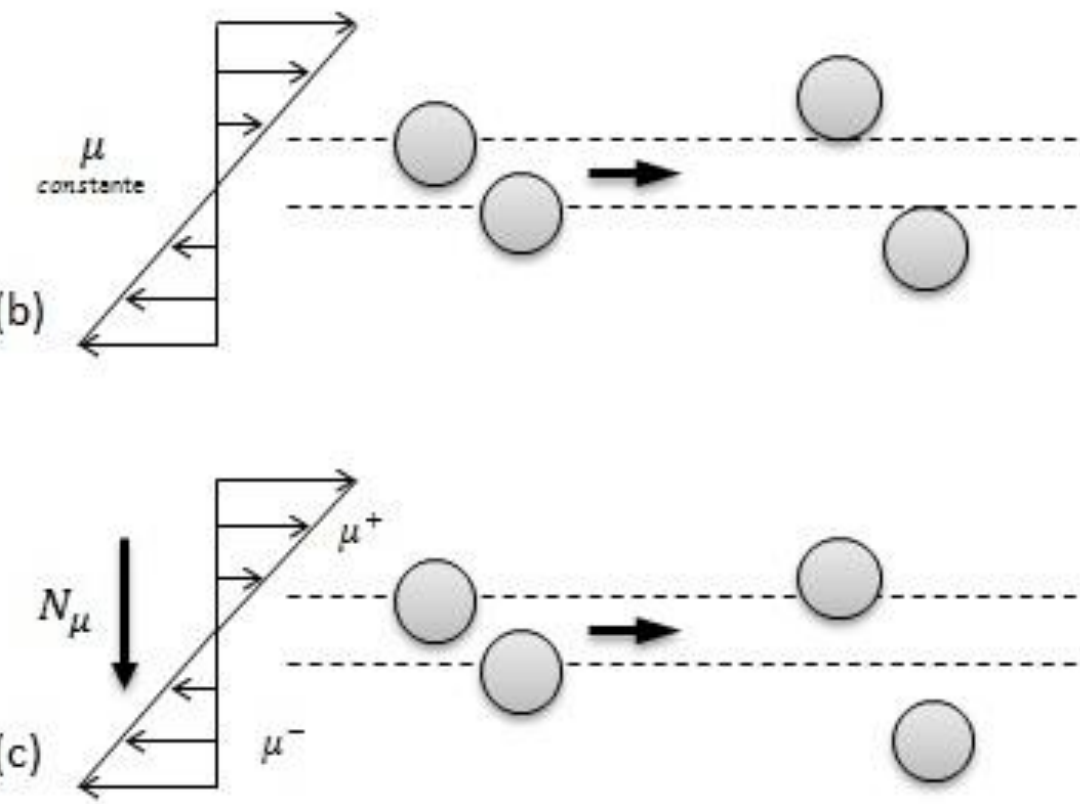

Figura 2-4 - Colisões irreversíveis entre dois corpos com (a) taxa de cisalhamento variável, (b) viscosidade constante e (c) variação espacial da viscosidade (Fonte: Phillips et al. 1992).

b. Efeito da variação espacial da viscosidade (migração induzida pelo gradiente de viscosidade): este mecanismo de migração ocorre devido à resistência ao movimento de uma partícula em regiões com maior viscosidade. Na Figura 2-4(b) há um fluxo com o campo de viscosidade constante onde após a colisão as duas partículas se deslocam da mesma forma, pois experimentam a mesma resistência ao movimento. Já na Figura 2-4(c), o campo de viscosidade é variável, portanto observamos que há um maior deslocamento das partículas na região de baixa viscosidade, ao contrário do que acontece nas regiões de viscosidade superior, pois 
elas retardam o movimento das partículas. A equação constitutiva resultante para o fluxo de partículas em função da variação espacial na viscosidade proposta por Phillips et al (1992) é:

$$
N_{\mu}=-K_{\mu} \dot{\gamma} \varnothing\left(\frac{a^{2}}{\mu}\right) \frac{d \mu}{d \emptyset} \nabla \emptyset
$$

onde $K_{\mu}$ é uma constante de proporcionalidade estabelecida experimentalmente. Nota-se que na equação, o gradiente de viscosidade é expresso em termos do gradiente de concentração, por causa da sua relação proporcional direta observada do modelo de viscosidade.

c. Efeito da sedimentação: este mecanismo é devido à diferença de densidade entre o líquido e as partículas, representado por Leighton e Acrivos (1986) da seguinte forma:

$$
N_{g}=\frac{2}{9} \varnothing f(\varnothing) \frac{a^{2} \Delta \rho}{\mu_{l}} \vec{g}
$$

onde $\mu_{l}$ é a viscosidade do líquido, $\Delta \rho$ é a diferença de densidade entre as fases líquida e sólida e $f(\varnothing)$ é a função que leva em conta a presença de outras partículas dentro da suspensão diminuindo o fluxo de partículas para regiões de alta concentração. Esta função é fortemente dependente da concentração $\emptyset$. Apesar de não se ter dados dessa função na presença de cisalhamento, por simplificação, Schaflinger et al (1990) adotou a função correspondente obtida em experimentos verticais, representada por:

$$
f(\varnothing)=\frac{1-\emptyset}{\mu_{r}}
$$

onde $\mu_{r}$ é a viscosidade efetiva, dada pela Eq.(2.10). 
Portanto, a Eq.(2.14) pode ser escrita da seguinte forma:

$$
N_{g}=\frac{2}{9} \frac{a^{2} \Delta \rho}{\mu_{l}} \emptyset \frac{(1-\emptyset)}{\mu_{r}} \vec{g}
$$

Deste modo, $N_{t}$ pode ser escrito como o somatório desses três mecanismos citados acima:

$$
N_{t}=N_{c}+N_{\mu}+N_{g}
$$

Retomando a Eq.(2.11), temos:

$$
\vec{v} \cdot \nabla \emptyset+\nabla \cdot\left(N_{c}+N_{\mu}+N_{g}\right)=0
$$

Assim, nosso sistema de equações finais que governam o problema é:

- Equação de Conservação de massa: Eq.(2.3)

- Equação de Conservação da Quantidade de Movimento: Eq.(2.4)

- Equação de transporte: Eq.(2.18)

Os parâmetros adimensionais que descrevem o escoamento são:

1. Número de Peclet Hidrodinâmido $(P e)$ : razão entre 0 transporte convectivo - difusivo de partículas da suspensão.

$$
P e=\frac{V \cdot H}{K_{c} \cdot a^{2} \cdot V / H}=\frac{H^{2}}{K_{c} \cdot a^{2}}
$$

2. Razão de difusividades ( $\lambda)$ : razão entre a constante de proporcionalidade do mecanismo de migração referente ao gradiente da taxa de cisalhamento $\left(K_{c}\right)$ e a constante de proporcionalidade referente à migração induzida pelo gradiente de viscosidade $\left(K_{\mu}\right)$.

$$
\lambda=\frac{K_{c}}{K_{\mu}}
$$


3. Número de sedimentação (s): razão entre os fluxos de sedimentação e convectivos.

$$
s=\frac{2}{9} \frac{a^{2} \cdot g \cdot \Delta \rho \cdot L}{H^{2} \cdot \Delta P}
$$

4. Diferencial de pressão adimensional:

$$
\Delta P^{*}=\frac{H}{\mu_{l}} \sqrt{\rho_{l} \cdot \Delta P}
$$

5. Vazão adimensional:

$$
Q^{*}=\frac{Q}{Q_{m}}=\frac{Q}{\frac{H^{3}}{12 \cdot \bar{\mu}} \cdot \frac{\Delta P}{L}}
$$

onde $\bar{\mu}$ é a viscosidade da suspensão para a concentração média de partículas.

6. Razão de aspecto do canal:

$$
L / H
$$

Através de dados da literatura ( $\mathrm{Li}, 2007)$, foi possível realizar uma estimativa dos valores de alguns desses parâmetros no caso real, como mostra a Tabela 2-1.

Tabela 2-1 - Comparação entre os valores de alguns adimensionais para o caso real e a dissertação.

\begin{tabular}{|ccc|}
\hline & Caso real & Dissertação \\
\hline$\lambda$ & $0,1 \leq \lambda<1$ & $0,1 \leq \lambda<1$ \\
\hline$\Delta P^{*}$ & $\sim 8000$ & $<3000$ \\
\hline $\mathrm{Pe}$ & $10^{2}-10^{5}$ & $10^{3}-10^{5}$ \\
\hline $\mathrm{S}$ & $\sim 10^{-9}$ & $10^{-5}-10^{-4}$ \\
\hline $\mathrm{Q}^{*}$ & $0,4-1,0$ & $0,03-1,2$ \\
\hline
\end{tabular}


Vale destacar que alguns valores estarão um pouco diferentes devido à limitação numérica do programa que não permitiu realizar simulações para grandes comprimentos de poço.

\section{3.}

\section{Condições de Contorno}

A Figura 2-5 apresenta o domínio do problema juntamente às condições de contorno utilizadas:

- Na entrada: perfil de velocidade desenvolvido; componente $v$ da velocidade nula; pressão de entrada, $P_{1}$, imposta e perfil de concentração constante, com $\emptyset_{m}$.

- Nas paredes: não deslizamento e sem fluxo de partículas.

- Na saída: pressão nula, $P_{2}$.

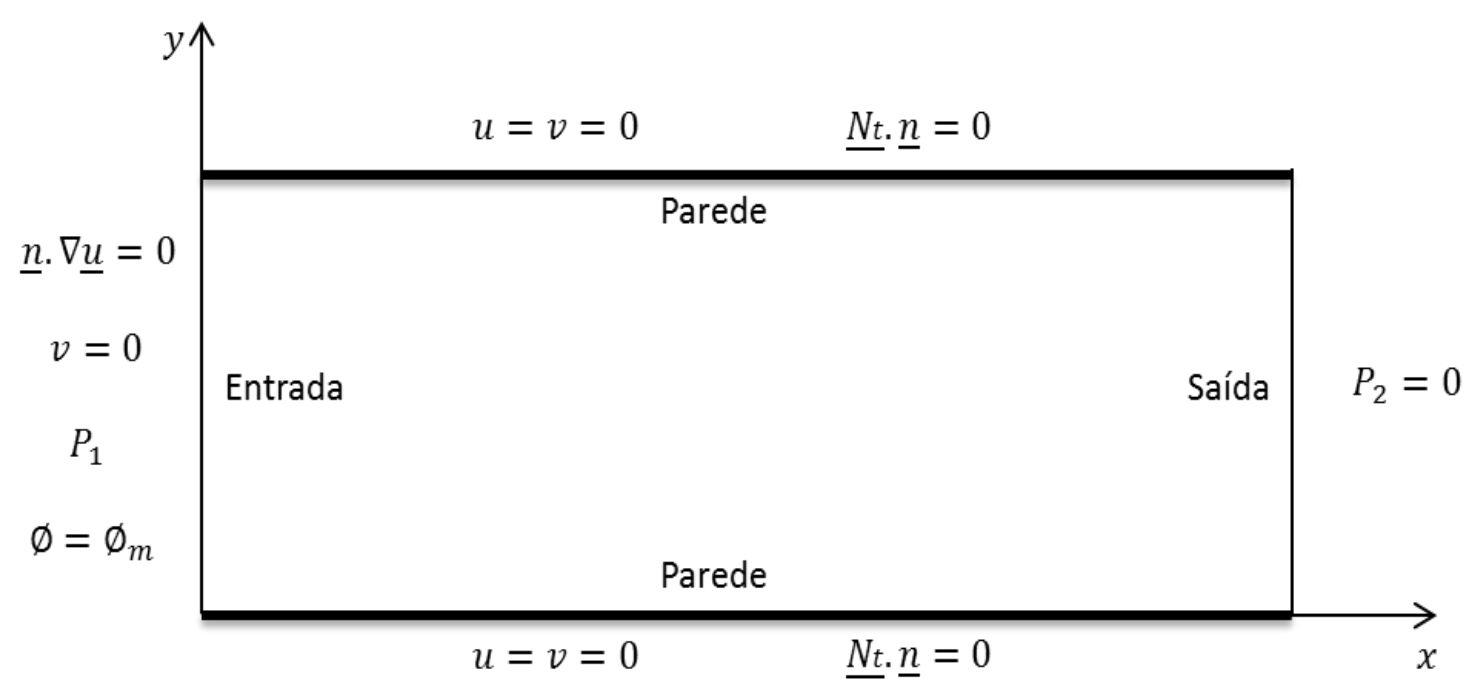

Figura 2-5 - Condições de contorno utilizadas no problema.

\section{4.}

\section{Método de Solução}

O sistema de equações diferenciais que governam o transporte de partículas é resolvido através do Método de Elementos Finitos. As equações de conservação de massa e quantidade de movimento e a equação de transporte foram resolvidas através do método de Galerkin. 


\subsection{1.}

\section{Solução através do método de Galerkin}

Para apresentar as funções peso e funções base é necessário dar atenção a uma particularidade deste problema. Na equação de transporte apresentada anteriormente, existe um termo proporcional ao divergente da derivada da taxa de deformação, sendo assim, dentro deste termo aparecerá uma derivada de terceira ordem do campo de velocidade, que, quando aplicado o teorema de divergência, será reduzida apenas a uma derivada de segunda ordem. Como as funções base utilizadas, nesse caso, para representar o campo de velocidade têm derivada descontinua no elemento de fronteira, faz-se necessário representar o gradiente de velocidade como um campo independente com uma interpolação continua, chamado $\overline{\bar{G}}$. A equação utilizada neste trabalho, que também foi adotada por Silva (2013), é:

$$
\overline{\bar{G}}=\nabla \vec{u}-\frac{\nabla \cdot \vec{u}}{\operatorname{tr} \overline{\bar{I}}}
$$

Juntamente com as Eq.(2.3), Eq.(2.4), Eq.(2.18) e as condições de contorno apropriadas, resolveu-se o sistema através do método de Galerkin e Petrov-Galerkin com elementos finitos quadrilaterais. As formulações fracas são representadas pelas seguintes equações:

$$
\begin{gathered}
R_{c}=\int_{\bar{\Omega}}(\nabla \cdot \vec{u}) \chi J_{T} d \bar{\Omega} \\
R_{m}=\int_{\bar{\Omega}}(\overline{\bar{T}}: \nabla \vec{W}) J_{T} d \bar{\Omega}-\int_{\bar{\Gamma}}(\vec{n} \cdot \overline{\bar{T}}) \cdot \vec{W}\left(\frac{d \Gamma}{d \bar{\Gamma}}\right) d \bar{\Gamma} \\
R_{t}=\int_{\bar{\Omega}}\left[(\vec{u} \cdot \nabla \emptyset) \varphi+\bar{D} \nabla \emptyset \cdot \nabla \varphi+K_{c} a^{2} \emptyset^{2} \nabla \dot{\gamma} \cdot \nabla \varphi\right. \\
\left.+\frac{2}{9} \emptyset f(\varnothing) \frac{a^{2}}{\mu_{l}} \Delta \rho \vec{g} \cdot \nabla \varphi\right] J_{T} d \bar{\Omega} \\
-\int_{\bar{\Gamma}}\left[\vec{n} \cdot\left(\bar{D} \nabla \emptyset+K_{c} a^{2} \emptyset^{2} \nabla \dot{\gamma}+\frac{2}{9} \emptyset f(\varnothing) \frac{a^{2}}{\mu_{l}} \Delta \rho \vec{g} \cdot \nabla \varphi\right)\right] \varphi\left(\frac{d \Gamma}{d \bar{\Gamma}}\right) d \bar{\Gamma}
\end{gathered}
$$


onde $\bar{D}$ equivale a seguinte expressão: $K_{c} a^{2} \emptyset \dot{\gamma}+K_{\mu} \dot{\gamma} \emptyset\left(\frac{a^{2}}{\mu}\right) \frac{d \mu}{d \emptyset}$.

$$
R_{G}=\int_{\bar{\Omega}}\left(\overline{\bar{G}}-\nabla \vec{u}+\frac{\nabla \cdot \vec{u}}{\operatorname{tr} \overline{\bar{I}}}\right) \cdot \vec{\psi} J_{T} d \bar{\Omega}
$$

onde $\vec{W}=\left(\varphi_{1}, \varphi_{2}\right)$ é o vetor da função peso da equação da conservação da quantidade de movimento, $\chi$ é a função peso equação da continuidade e $\vec{\psi}=\left(\psi_{1}, \psi_{2}\right)$ é o vetor da função peso para a interpolação da equação do gradiente de velocidade.

Os campos desconhecidos são agora representados como uma combinação linear de funções base, sendo essas iguais as funções peso correspondentes (fundamento do método de Galerkin).

Esses campos desconhecidos (velocidades u e v, pressão p, concentração de partículas $\varnothing$ e gradientes de velocidade interpolados $G_{u x}, G_{u y}, G_{v x}$ e $G_{v y}$ ) são escritos da seguinte forma:

$$
\begin{gathered}
u=\sum_{j=1}^{n}\left(U_{j} \varphi_{j}\right), \quad v=\sum_{j=1}^{n}\left(V_{j} \varphi_{j}\right) \\
p=\sum_{j=1}^{m}\left(P_{j} \chi_{j}\right) \\
\emptyset=\sum_{j=1}^{n}\left(\emptyset_{j} \varphi_{j}\right) \\
G_{u x}=\sum_{j=1}^{l}\left(G u x_{j} \psi_{j}\right), \quad G_{u y}=\sum_{j=1}^{l}\left(G u y_{j} \psi_{j}\right) \\
G_{v x}=\sum_{j=1}^{l}\left(G v x_{j} \psi_{j}\right), \quad G_{v y}=\sum_{j=1}^{l}\left(G v y_{j} \psi_{j}\right)
\end{gathered}
$$

As funções base utilizadas para representar as variáveis independentes dentro de cada elemento são: $\varphi_{j}(\xi, \eta)$ polinômios lagrangeanos biquadráticos; $\chi_{j}(\xi, \eta)$ funções base linear descontinua e $\psi_{j}(\xi, \eta)$ polinômios lagrangeanos bilineares.

Os coeficientes da combinação linear das funções base que representam as incógnitas do problema discreto são: $U_{j}, V_{j}, P_{j}, \phi_{j}, X_{j}, Y_{j}, G u x_{j}, G u y_{j}, G v x_{j} e G v y_{j}$. 
As funções base descritas estão associadas com um elemento quadrilateral com 9 nós e 64 graus de liberdade. Dentro de cada elemento os graus de liberdade locais são enumerados como mostra a Tabela 2-2.

A escolha da combinação de funções base não é arbitrária porque a convergência do método pode ser prejudicada. A combinação de uma função de interpolação para velocidade e linear descontinua para pressão na solução de fluxo de fluido para problema com fluidos Newtonianos fornece bons resultados em relação a outras alternativas (Sani et al, 1981).

Tabela 2-2 - Graus de Liberdade de cada elemento.

\begin{tabular}{|cc|}
\hline Variável & Numeração Local \\
\hline $\mathbf{v}$ & $1-9$ \\
\hline $\mathbf{u}$ & $10-18$ \\
\hline$\varnothing$ & $19-27$ \\
\hline$p$ & $28-30$ \\
\hline Gux & $31-34$ \\
\hline Guy & $35-38$ \\
\hline Gvx & $39-42$ \\
\hline Gvy & $43-46$ \\
\hline
\end{tabular}

\subsection{2.}

\section{Solução do sistema de equações lineares pelo método de Newton}

Os resíduos ponderados são integrados numericamente através do Método da Quadratura Gaussiana, com três pontos de integração em cada direção.

O sistema de equações diferenciais parciais é transformado em um sistema de equações algébricas não lineares quando as variáveis independentes são escritas em termos da combinação de funções base, cuja representação em notação compacta é:

$$
\vec{R}(\vec{c} ; \vec{p})=0
$$

onde $\vec{R}$ é o vetor de resíduos ponderados, $\vec{c}$ é o vetor solução, que contem os coeficientes das funções base que são as incógnitas do problema, e $\vec{p}$ é o vetor dos parâmetros que controlam o problema. Esta equação é resolvida através do método iterativo de Newton, descrito como: 


$$
\begin{aligned}
& J \delta \vec{c}=-\vec{R}(\vec{c} ; \vec{p}) \\
& \delta \vec{c}=\vec{c}^{k+1}-\vec{c}^{k}
\end{aligned}
$$

J é a matriz jacobiana cujos componentes são dados por:

$$
J \equiv \frac{\partial \overrightarrow{R_{l}}}{\partial \overrightarrow{c_{J}}}
$$

Neste trabalho os componentes de $J$ são calculados numericamente através do esquema de diferenças centrais:

$$
J_{i j}=\frac{R_{i}\left(c_{1}, \ldots, c_{j}+\epsilon, \ldots\right)-R_{i}\left(c_{1}, \ldots, c_{j}-\epsilon, \ldots\right)}{2 \epsilon}
$$

assumindo $\epsilon=10^{-6}$.

A iteração começa com um valor inicial estimado para $c^{0}$ e continua até que a equação da notação compacta (Eq.(2.34)) seja aproximadamente satisfeita, ou seja, até o ponto em que a norma $L_{2}$ do vetor resíduo satisfaça a desigualdade $\|R\|_{2} \leq 10^{-6}$.

O código computacional utilizado nesta pesquisa é uma extensão do programa desenvolvido por Carvalho (1996) e Romero (2003), escrito em Fortran77/90. Este programa tem sido amplamente testado tanto para fluidos newtonianos quanto para fluidos não Newtonianos em diferentes geometrias e com superfícies livres. O modelo de transporte de partículas em uma suspensão foi recentemente incorporado ao código por Silva (2013) e Araujo (2014).

O programa utilizado é composto por três partes principais: PREPRO (préprocessador), SOLVER (solução) e POSTPRO (pós-processador). No PREPRO são definidos parâmetros tais como: a geometria, número de regiões, número de elementos, conectividade, tipo de fluido e condições de contorno. Então, os campos de interesse são obtidos pelo SOLVER. E, finalmente, o POSTPRO gera os arquivos que serão visualizados pelo software Tecplot 360 . 


\section{3 \\ Resultados}

Neste capítulo serão apresentados e discutidos os resultados obtidos. O transporte de partículas é estudado em função dos parâmetros do problema: comprimento do canal, diferença de densidade entre o fluido e as partículas, constantes $K_{c}$ e $K_{\mu}$ do fluxo por gradiente de taxa de cisalhamento e viscosidade e a variação do diferencial de pressão, que afeta diretamente a vazão do fluxo. $O$ sistema de unidades adotado foi o Sistema Internacional (SI).

Primeiramente, realizou-se um teste de malha para verificar qual o tamanho da malha seria utilizado. Para este teste, começamos com um malha de 10 elementos na direção y e 30 elementos na direção x. Os números de elementos em cada direção foram alterados e assim avaliaram-se a solução obtida com três malhas diferentes, como mostra a tabela abaixo:

Tabela 3-1 - Dados utilizados para o teste de malhas.

\begin{tabular}{|ccccc|}
\hline Malha & \# elem. em y & \# elem. em x & \# elem. total & $\Delta \rho_{\text {máx }}\left(\mathbf{k g} / \mathbf{m}^{\mathbf{3}}\right)$ \\
\hline M1 & 10 & 30 & 300 & 0,87 \\
\hline M2 & 15 & 40 & 600 & 0,94 \\
\hline M3 & 20 & 50 & 1000 & 0,96 \\
\hline
\end{tabular}

Esses testes foram realizados com os seguintes dados: $\triangle P=150 \mathrm{~Pa}$; $K_{c}=0,043 ; K_{\mu}=0,065$ e viscosidade do fluido de 0,1 Pa.s.

A Tabela 3-1 apresenta o valor máximo da diferença de densidade entre o fluido e as partículas $(\Delta \rho)$ abaixo da qual uma solução pode ser obtida para cada uma das malhas. Observa-se na Tabela 3-1, que quanto mais refinada é a malha, maior o valor de $\Delta \rho$ que se consegue alcançar. $O$ limite de convergência ocorre devido aos altos gradientes de concentração que ocorrem quando a intensidade da sedimentação é alta ( $\Delta \rho$ grande). Quanto mais refinada a malha, maiores são os valores dos gradientes de concentração que precisam ser calculados. Desta forma, observa-se que o problema de convergência do programa diminui ao refinarmos mais a malha. 


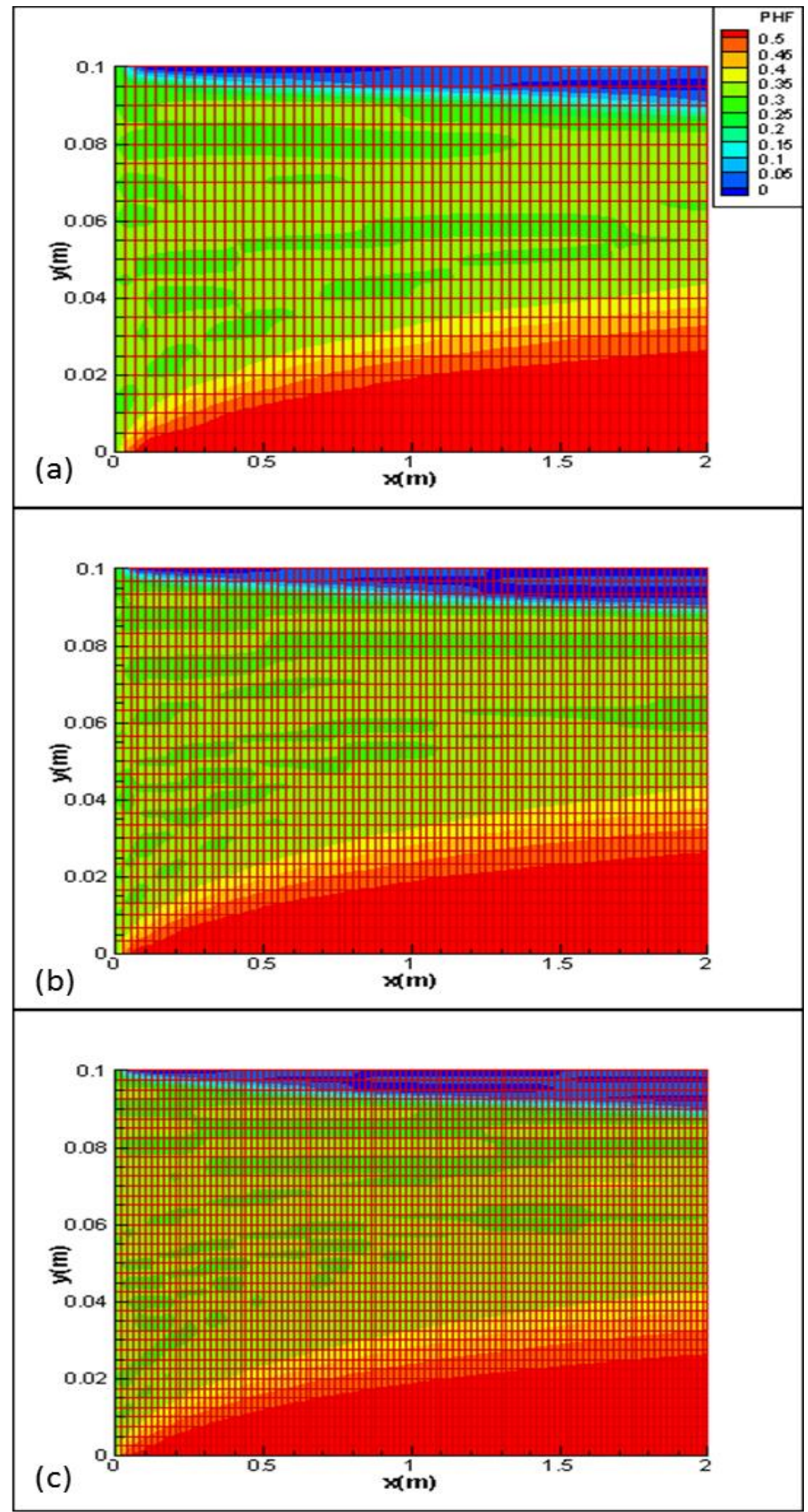

Figura 3-1 - Perfis de concentração ao longo do canal para o teste de malha, onde

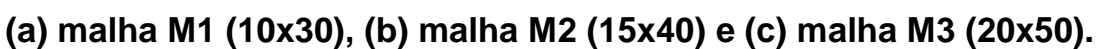


A Figura 3-1 apresenta o campo de concentração de partículas para $\Delta P=150 P a, K_{c}=0,043, K_{\mu}=0,065, \mu=0,1 P a . s$ e $\emptyset_{m}=0,3$, obtido com as três malhas diferentes, para os valores máximos de $\Delta \rho$ abaixo do qual obteve-se solução. O perfil de concentração no plano da saída é apresentado na Figura 3-2. Observou-se claramente o efeito de sedimentação de partículas formando um leito de alta concentração na parte inferior do canal e uma pequena região sem partículas (concentração igual a zero) próxima da parede superior, além da influência dos outros dois mecanismo de migração que empurram as partículas para regiões de menores gradientes de concentração e de taxa de cisalhamento, formando aqueles picos logo acima do centro do canal. Pode-se observar que a solução obtida foi praticamente a mesma com as três malhas. Como o interesse é de analisar a maior faixa possível de parâmetros, optou-se por usar a malha mais refinada, $\mathrm{M} 3$.

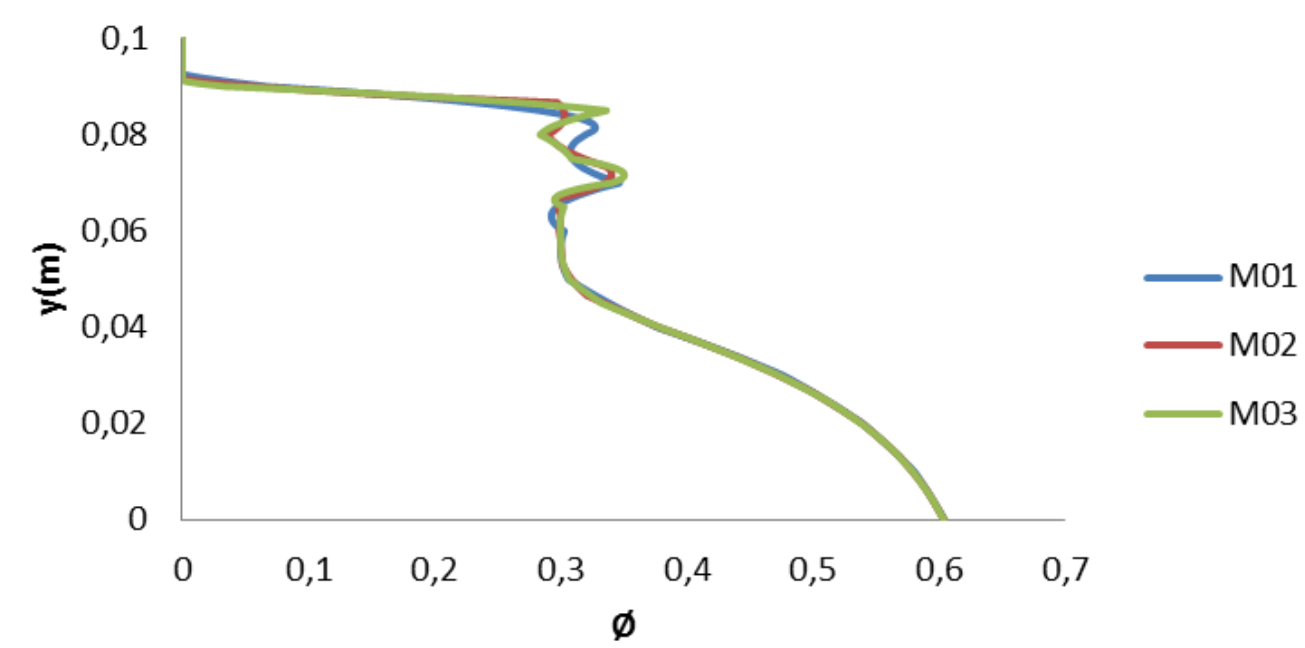

Figura 3-2 - Perfis de concentração na saída do canal para os três tamanhos de malha testados.

Decidindo-se pela malha, o próximo passo foi escolher qual comprimento do canal seria utilizado para os demais cálculos. Optou-se por pequenos comprimentos de $\mathrm{L}$ para as análises das variáveis, visto que para esses comprimentos foi possível alcançar uma maior variação nos valores dos parâmetros, como será apresentado nas seguintes seções.

Nas próximas seções iremos destacar o comportamento da concentração das partículas em função do comprimento do canal, da diferença de densidade 
entre o fluido e o líquido, dos valores dos coeficientes de difusão e da diferença de pressão imposta.

Nos próximos cálculos alguns dados foram mantidos constantes, são eles:

- Raio das partículas: $a=4 \mathrm{~mm}$

- Altura do canal: $H=0,1 \mathrm{~m}$

- Viscosidade do fluido: $\mu=0,1$ Pa.s

- Concentração de partículas na entrada do canal: $\emptyset_{m}=0,3$

\section{1.}

\section{Efeito do comprimento do canal}

Sabe-se que, com o frequente desenvolvimento da tecnologia, os poços de petróleo horizontais atingem cada vez mais longas distâncias. Desta forma, é importante estudar a evolução da altura do leito de partículas ao longo do comprimento do canal. Como foi observada uma limitação na convergência da solução para grandes comprimentos (com mesmo número de elementos), foi necessário verificar se a solução obtida variava com o comprimento do canal.

As Figura 3-3 e Figura 3-4 mostram a análise realizada para canais de 2 e 4 metros de comprimento. Os valores dos parâmetros utilizados nesta simulação foram:

- $K_{c}=0,043$

- $K_{\mu}=0,065$

- $\Delta \rho=0,30 \mathrm{~kg} / \mathrm{m}^{3}$

Tabela 3-2 - Dados utilizados para as simulações que comparam os diferentes comprimentos do canal.

\begin{tabular}{|cccc|}
\hline Canal & $L(m)$ & $\Delta P(P a)$ & $s$ \\
\hline$C 1$ & 2 & 69 & $3,03 \mathrm{E}-05$ \\
\hline$C 2$ & 4 & 155 & $2,70 \mathrm{E}-05$ \\
\hline
\end{tabular}

Como pode ser observado através da Tabela 3-2, por causa da diferença no comprimento do canal nos dois casos, para que a vazão de fluxo fosse mantida igual, neste caso $Q \cong 0,0083 \mathrm{~m}^{2} / \mathrm{s}$, foi preciso alterar o valor do diferencial de pressão imposta. 
A Figura 3-3 mostra o comportamento da concentração de partículas ao longo do canal para os dois comprimentos diferentes. É possível observar, com o auxílio Figura 3-4, que, independentemente do comprimento do canal, quando a vazão de fluxo é igual nos dois casos o comportamento do perfil de concentração em qualquer ponto, ao longo de x, também será igual. A Figura 3-4 apresenta o perfil de concentração em $x=2 m$ para os dois casos, mostrando que o comprimento do canal não afeta a solução do problema.

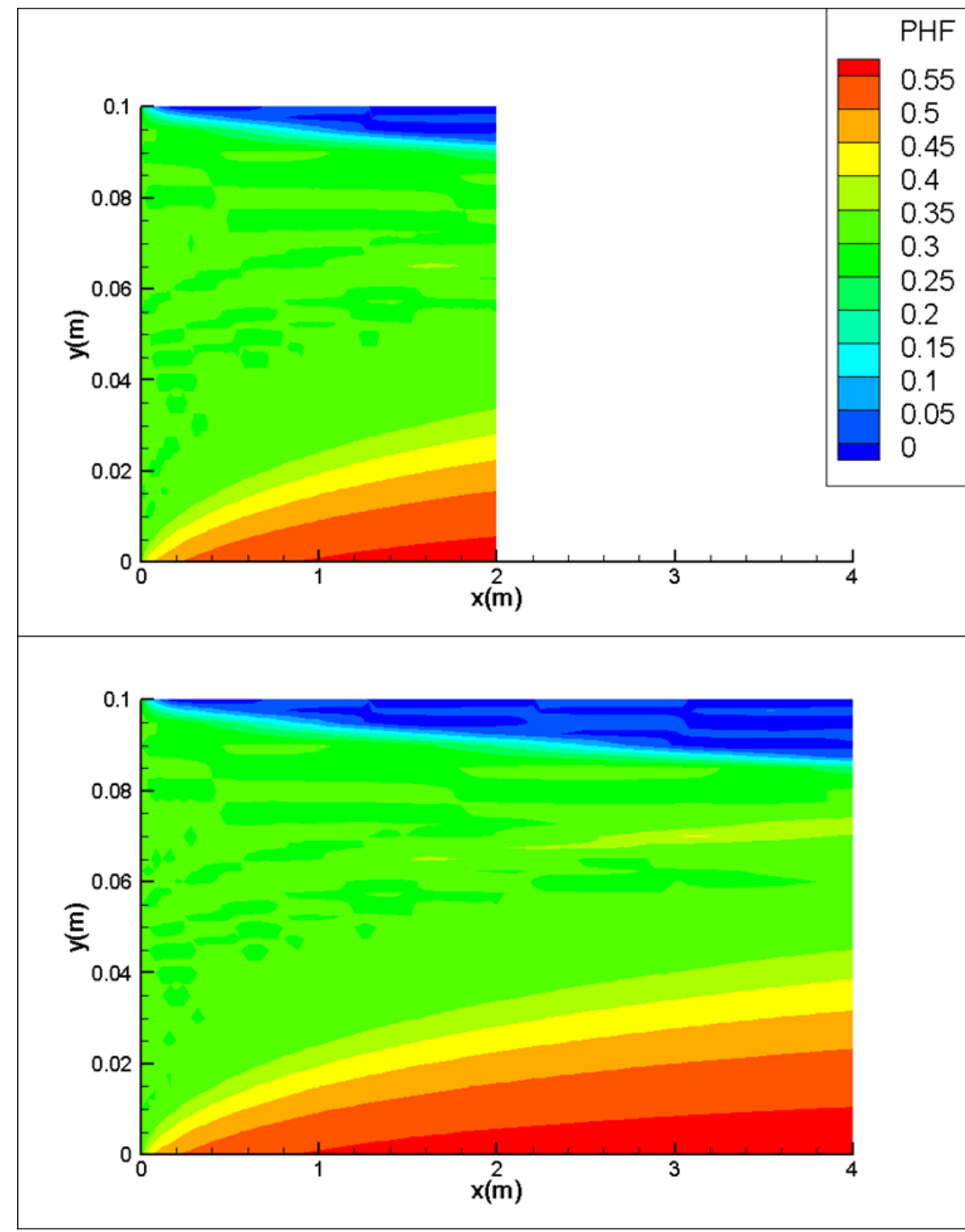

Figura 3-3 - Perfis de concentração ao longo do canal para os comprimentos de: (a) 2 metros e (b) 4 metros. 


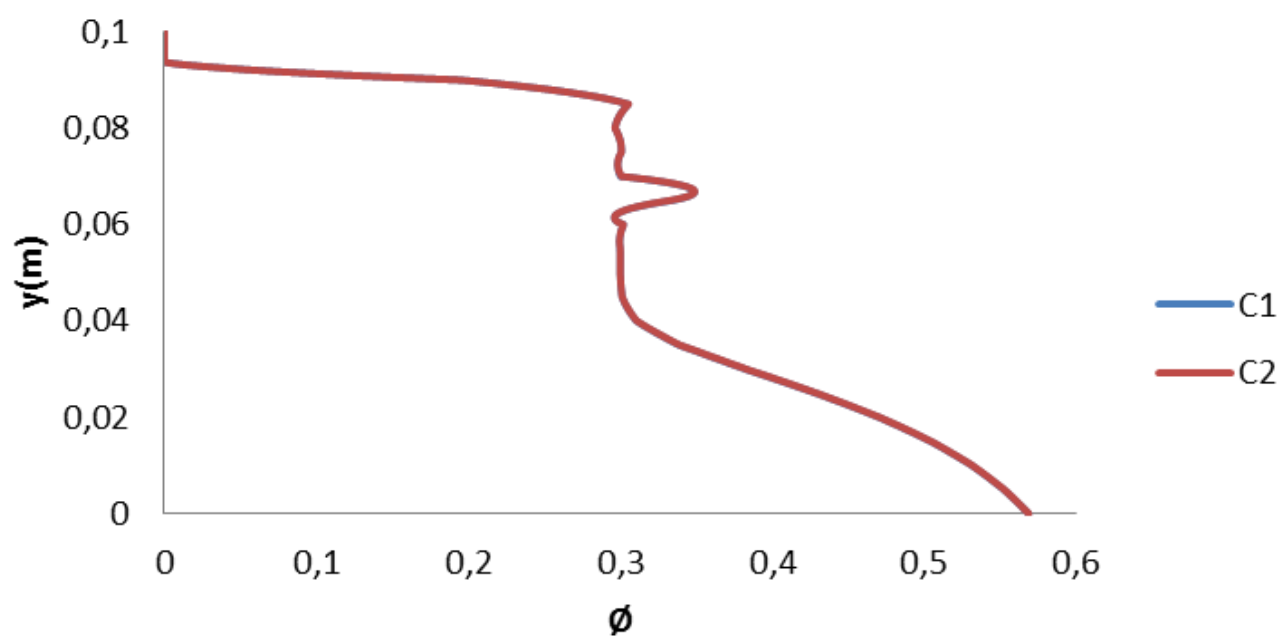

Figura 3-4 - Perfil de concentração para os dois casos no ponto em $x=2$ metros.

Através deste resultado, conclui-se que o estudo da evolução do leito de partículas pode ser feito para menores valores do comprimento de canal sem comprometer a análise. Outro fato que contribuiu para a escolha do comprimento do canal foi que para canais menores conseguiu-se aumentar mais a diferença de densidade entre as partículas e o fluido, para mesmas condições de fluxo. Nesses dois casos acima se observou que para o canal de comprimento igual a 4 metros o $\Delta \rho$ máximo, para o qual obteve-se solução, foi de $0,37 \mathrm{~kg} / \mathrm{m}^{3}$, enquanto que para o canal de comprimento igual a $2 \mathrm{~m}$, foi de $0,46 \mathrm{~kg} / \mathrm{m}^{3}$.

Esta mesma análise foi realizada para outros dois comprimentos, apenas com o objetivo de confirmação. Utilizaram-se canais com comprimento de $10 \mathrm{e}$ 15 metros. Para estes casos $\lambda=0,66$ e $\Delta \rho=0,02 \mathrm{~kg} / \mathrm{m}^{3}$.

Tabela 3-3 - Dados utilizados para as simulações que comparam os diferentes comprimentos do canal.

\begin{tabular}{|ccc|}
\hline Canal & $L(m)$ & $\Delta P(P a)$ \\
\hline$C 3$ & 10 & 400 \\
\hline$C 4$ & 15 & 600 \\
\hline
\end{tabular}


Observou-se, novamente que, desde que todos os parâmetros sejam iguais e o escoamento esteja a uma mesma vazão, neste caso $Q \cong 0,0116 \mathrm{~m}^{2} / \mathrm{s}$, não importa o comprimento do canal o perfil de concentração será igual, como mostra a Figura 3-5. A Figura 3-6 compara o perfil de velocidade para os dois casos.

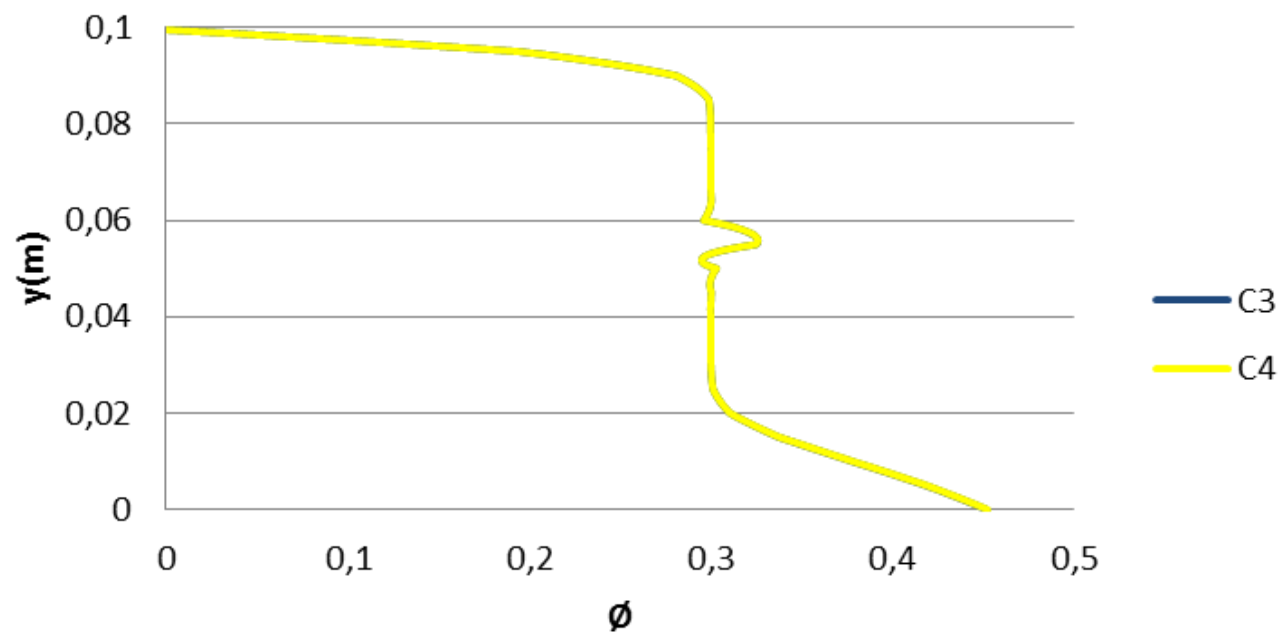

Figura 3-5 - Perfis de concentração dos dois canais em $x=10 m$.

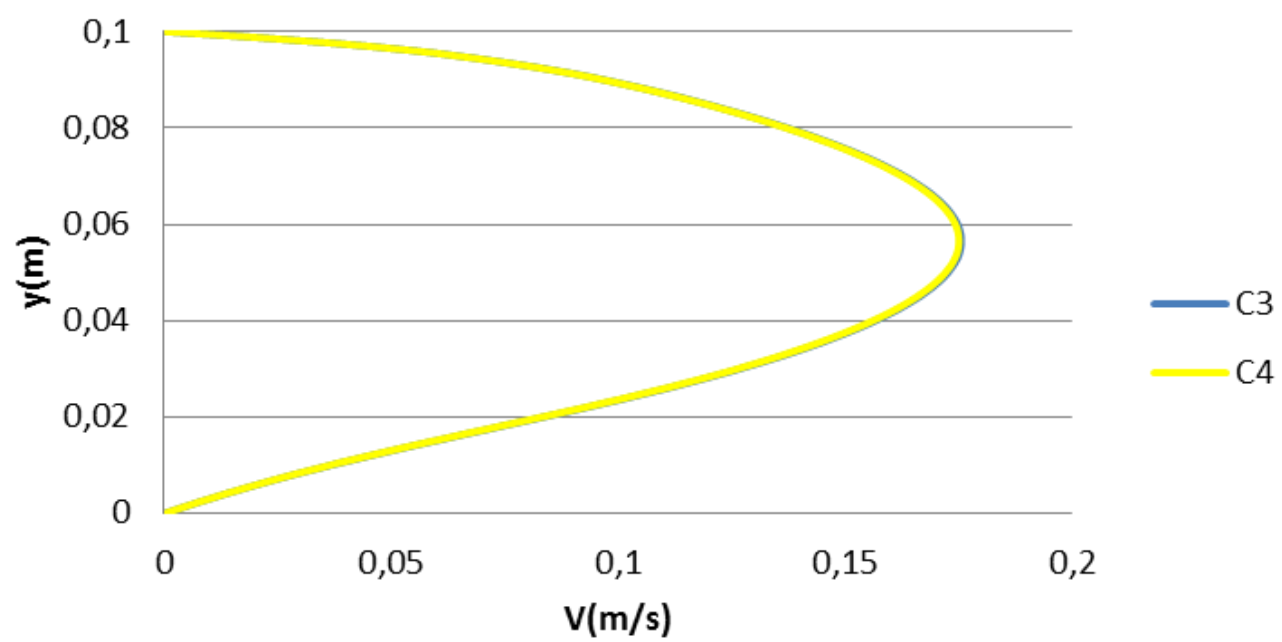

Figura 3-6 - Perfis de velocidade dos dois canais em $x=10 m$. 


\section{2.}

\section{Efeito da variação da densidade das partículas}

O objetivo nesta seção é avaliar o transporte de partículas sólidas em função da densidade das mesmas. Os testes foram realizados para o canal de comprimento igual a 2 metros, com um diferencial de pressão entre a entrada e a saída do canal de $80 \mathrm{~Pa}$. Realizaram-se testes para dois casos com diferentes valores das constantes de difusão:

$$
\begin{aligned}
& \text { 1. } K_{c}=0,043 \text { e } K_{\mu}=0,065 \\
& \text { 2. } K_{c}=0,120 \text { e } K_{\mu}=0,180
\end{aligned}
$$

Em cada um dos casos foram escolhidos três valores diferentes de $\Delta \rho$ para a análise do comportamento do escoamento.

A primeira análise realizada foi do caso onde $K_{c}$ e $K_{\mu}$ valem 0,043 e 0,065, respectivamente. Os valores dos parâmetros adimensionais são: $\lambda=0,66$; $P e=14534,9$ e $\Delta P^{*}=282,84$. Os diferentes valores do parâmetro adimensional de sedimentação $s$ para cada valor de $\Delta \rho$, são apresentados na Tabela 3-4.

Tabela 3-4 - Dados do primeiro conjunto de simulações para diferentes valores de $\Delta \rho$.

\begin{tabular}{|ccc|}
\hline Caso & $\Delta \rho\left(\mathrm{kg} / \mathrm{m}^{3}\right)$ & $\mathrm{s}$ \\
\hline C1.1 & 0,1 & $8,76.10^{-6}$ \\
\hline C1.2 & 0,3 & $2,62.10^{-5}$ \\
\hline C1.3 & 0,56 & $4,88.10^{-5}$ \\
\hline
\end{tabular}

Observa-se na Figura 3-7 que, à medida que se aumenta a densidade das partículas (aumentando-se também o parâmetro s) elas se depositam em maior quantidade no fundo do canal. Isso ocorre porque elas passam a sofrer uma maior ação do efeito de migração devido à gravidade, que as empurra para baixo. Pode-se notar na Figura 3-7(a) que quando a diferença entre a densidade das partículas e a do fluido é pequena, as partículas quase não sofrem o efeito da gravidade e o escoamento é praticamente simétrico em relação ao centro do canal. As maiores concentrações são encontradas no centro do canal, devido ao efeito de migração pela frequência de interações, que levam as partículas para as regiões de menor cisalhamento. À medida que a densidade das partículas aumenta esse efeito perde forças e através da ação da gravidade as partículas se depositam no fundo do canal. 

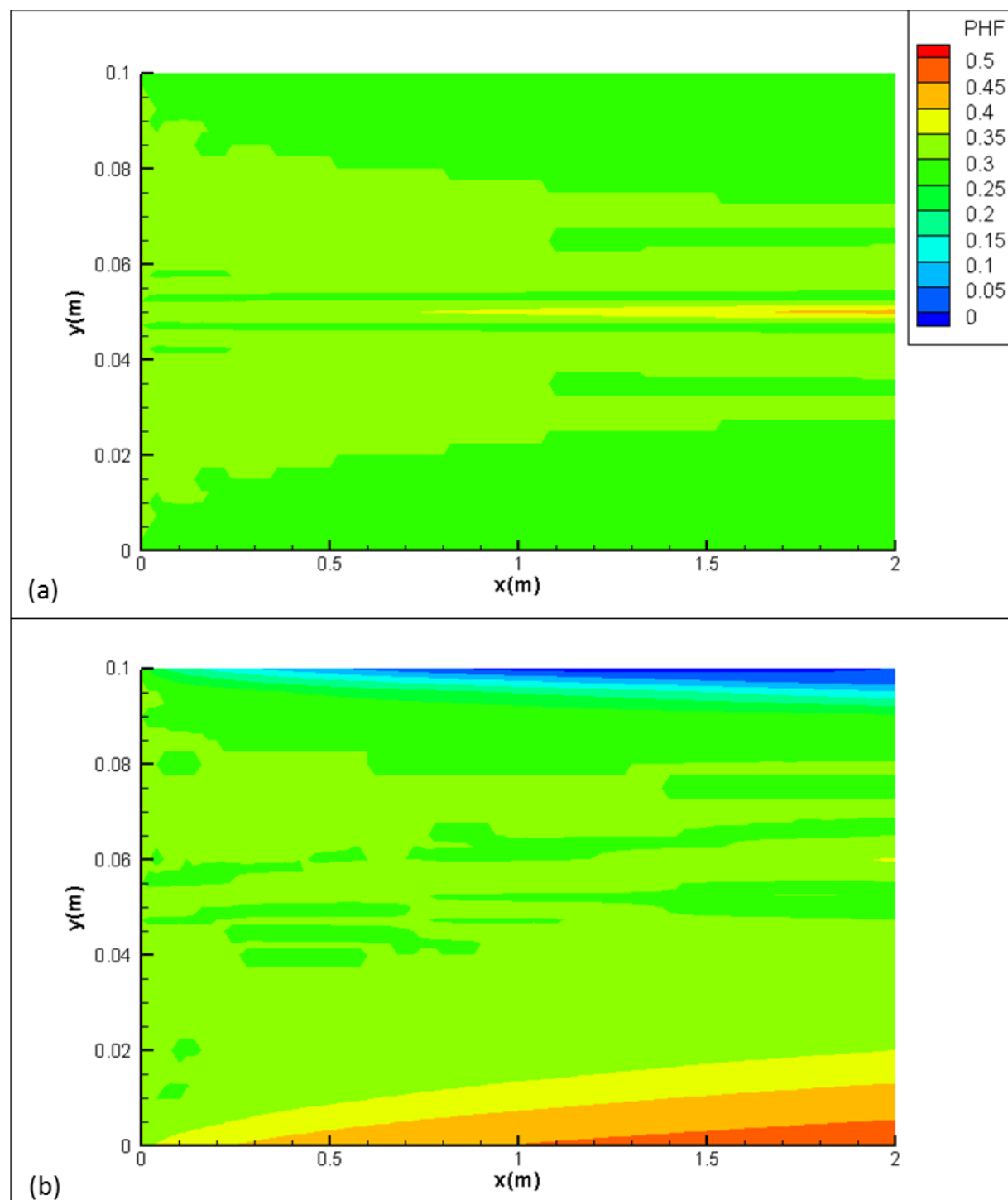

(b)

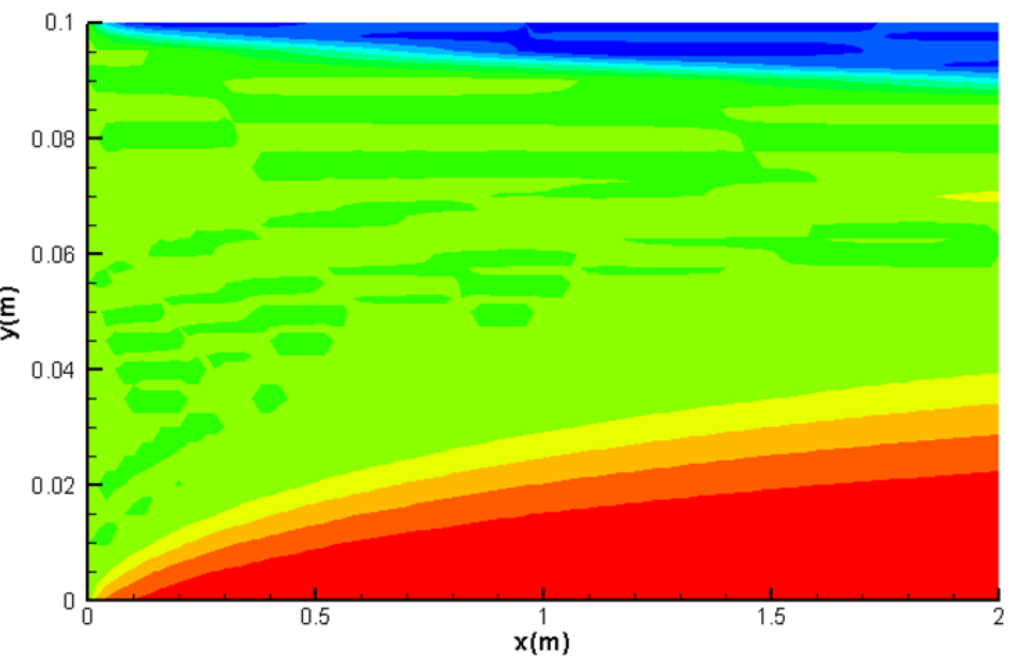

Figura 3-7 - Perfil de concentração ao longo do canal para os casos com $s$ igual a: (a) $8,76.10^{-6}$; (b) $2,62.10^{-5}$ e (c) $4,88.10^{-5}$. 
A Figura 3-8 mostra o perfil de concentração na saída do canal para os diferentes valores de $s$. Pode-se observar que para o caso em que $s=$ $8,76.10^{-6}$, no centro do canal ocorre um pico de concentração que chega a pouco mais de 0,4 , enquanto que nas extremidades essa concentração se reduz a aproximadamente 0,25 , já que essas partículas sofrem mais a ação do efeito da variação espacial da frequência de interações que levam as partículas para as regiões de menor cisalhamento, ou seja para o centro do canal. À medida que $s$ aumenta, o efeito de sedimentação atua mais intensamente levando as partículas ao fundo do canal, como vemos no caso em que $s=4,88 \cdot 10^{-5}$. Neste caso já é possível observar no topo do canal uma região sem a presença das partículas, ou seja, concentração igual a zero, e uma região perto da parede inferior onde a concentração é maior que 0,5 , formando um leito quase estático de sedimentos.

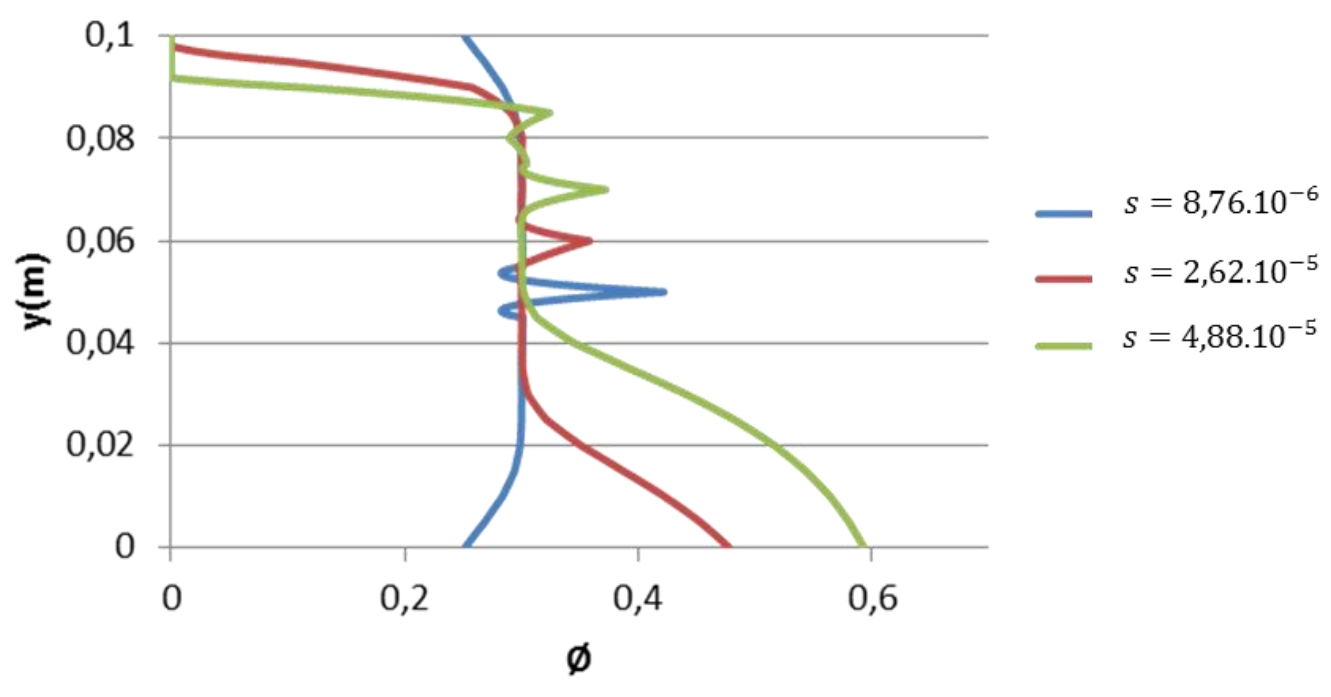

Figura 3-8 - Perfis de concentração na saída do canal para os casos em que a densidade das partículas é alterada.

As diferenças existentes nos perfis de velocidade apresentados na Figura 3-9, mostram que a alteração na densidade das partículas promove uma mudança na vazão, para um diferencial de pressão fixo. Com os valores de $Q^{*}$ iguais a 1,19;1,12 e 0,84 respectivamente, é correto afirmar que à medida que se aumenta o $\Delta \rho$ diminui-se a vazão. Isto ocorre devido ao bloqueio na base do canal através da formação do leito sedimentado das partículas. 


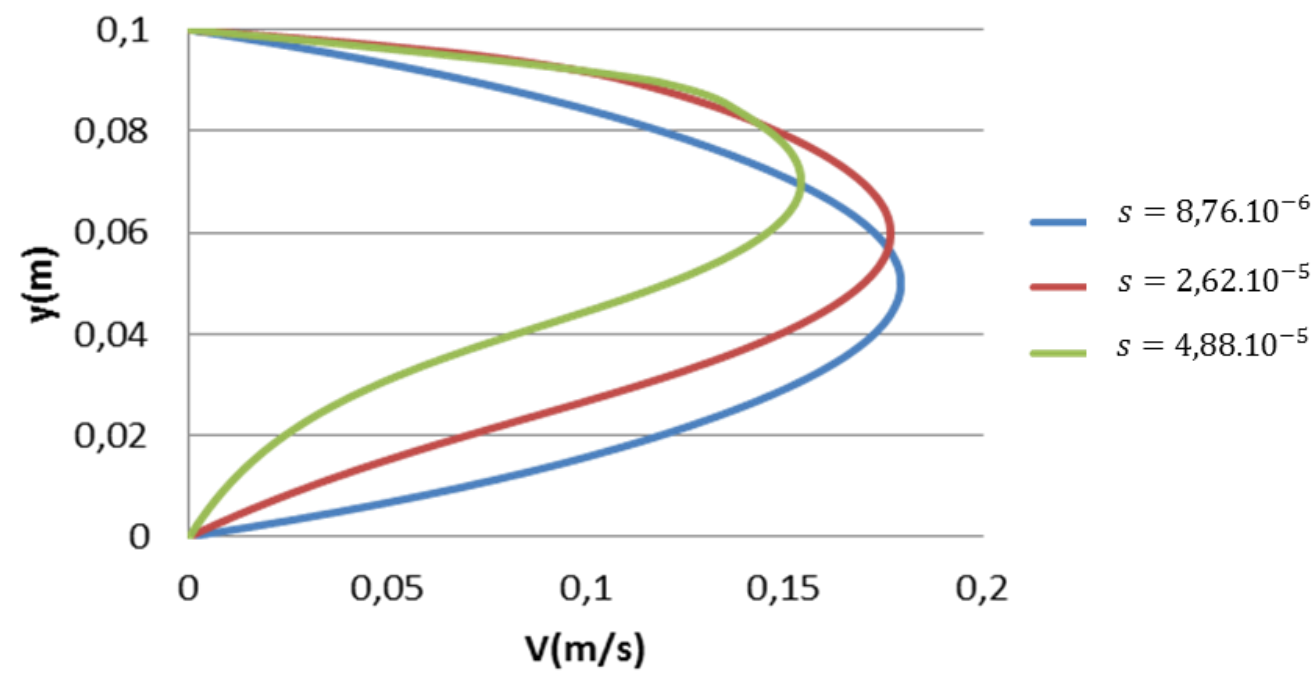

Figura 3-9 - Perfis de velocidade na saída do canal para os casos em que a densidade das partículas é alterada.

Com o intuito de descobrir se esse comportamento também ocorre para outros valores dos parâmetros, mais um teste foi realizado, agora para maiores valores dos coeficientes de difusão, $K_{c}=0,12$ e $K_{\mu}=0,18$. Como poderá ser observado nos gráficos abaixo, os resultados mantêm o mesmo comportamento. Os valores dos parâmetros adimensionais foram: $P e=5208,3, \lambda=0,66 \mathrm{e}$ $\Delta P^{*}=282,84$. Os demais dados estão contidos na Tabela 3-5.

Tabela 3-5 - Dados do segundo conjunto de simulações para diferentes valores de $\Delta \rho$.

\begin{tabular}{|ccc|}
\hline Caso & $\Delta \rho\left(\mathrm{kg} / \mathrm{m}^{3}\right)$ & $s$ \\
\hline C1.4 & 0,32 & $2,79.10^{-5}$ \\
\hline C1.5 & 0,64 & $5,58.10^{-5}$ \\
\hline C1.6 & 0,96 & $8,37.10^{-5}$ \\
\hline
\end{tabular}

A Figura 3-10 mostra a evolução da sedimentação das partículas ao longo do canal, com o incremento na densidade das mesmas. Nota-se claramente, que quanto maior a densidade das partículas mais elas se depositaram no fundo do canal. 


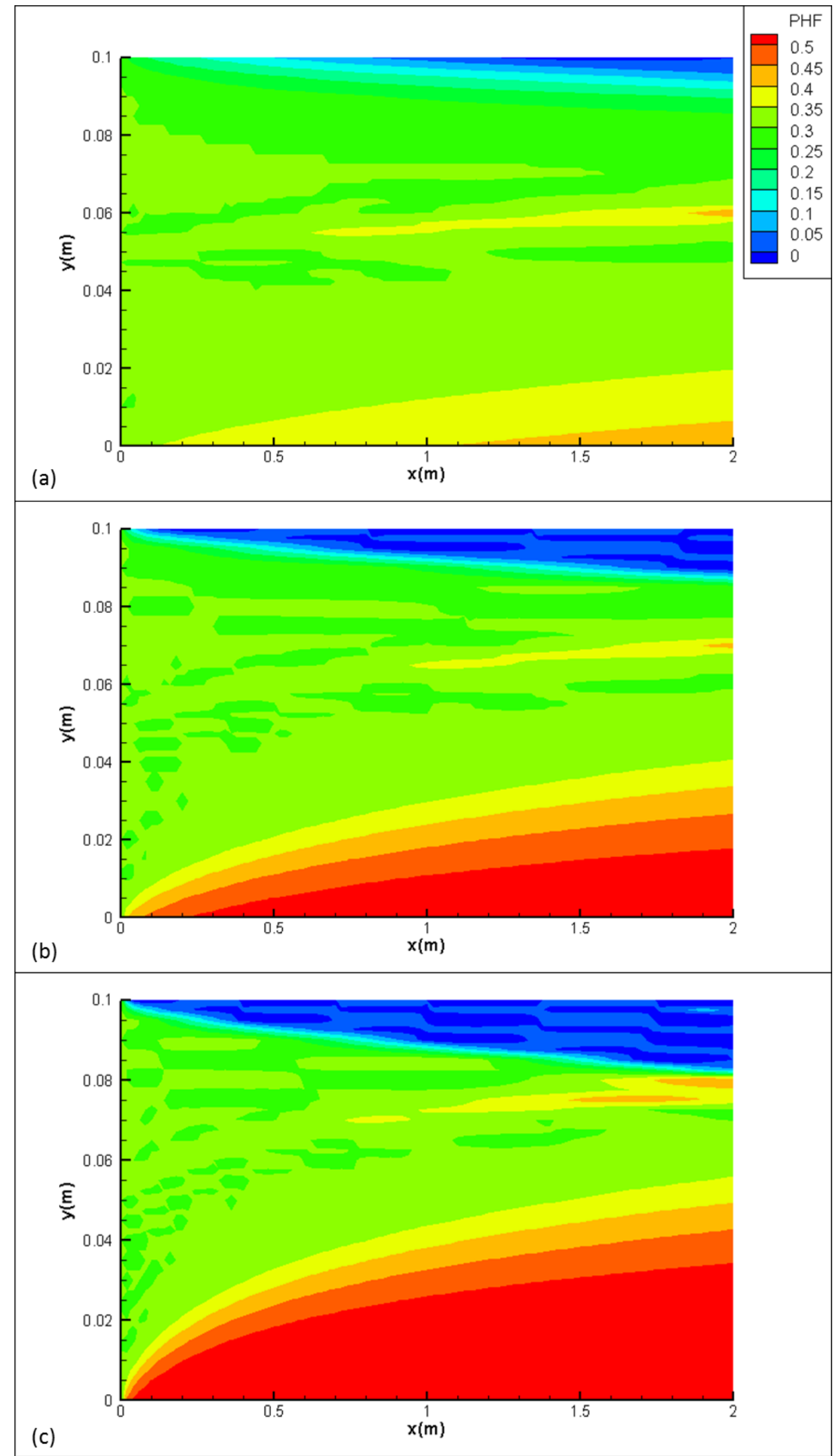

Figura 3-10 - Perfis de concentração ao longo do canal para os casos com $s$ igual a: (a) $2,79.10^{-5}$ (b) $5,58.10^{-5}$ e (c) $8,37.10^{-5}$. 
Como destacado anteriormente, existe uma determinada concentração a partir da qual a viscosidade da suspensão cresce tão rapidamente que a mesma se comporta como um fluido altamente viscoso, o que não permite que elas sejam transportadas pelo fluido. A concentração a partir da qual isto passa a ocorrer é de aproximadamente 50\%. A Figura 3-11 apresenta a isso-linha de $\emptyset=0,5$, que representa a superfície do leito de partículas. Observa-se que para $s=2,79 \cdot 10^{-5}$, a concentração ao longo do canal é inferior a $50 \%$ e assim todas as partículas fluem livremente pelo canal, sendo que à medida que se incrementa o valor de $s$ o leito vai se formando. No caso de maior $s$ o leito já obstrui $40 \%$ da saída do canal.

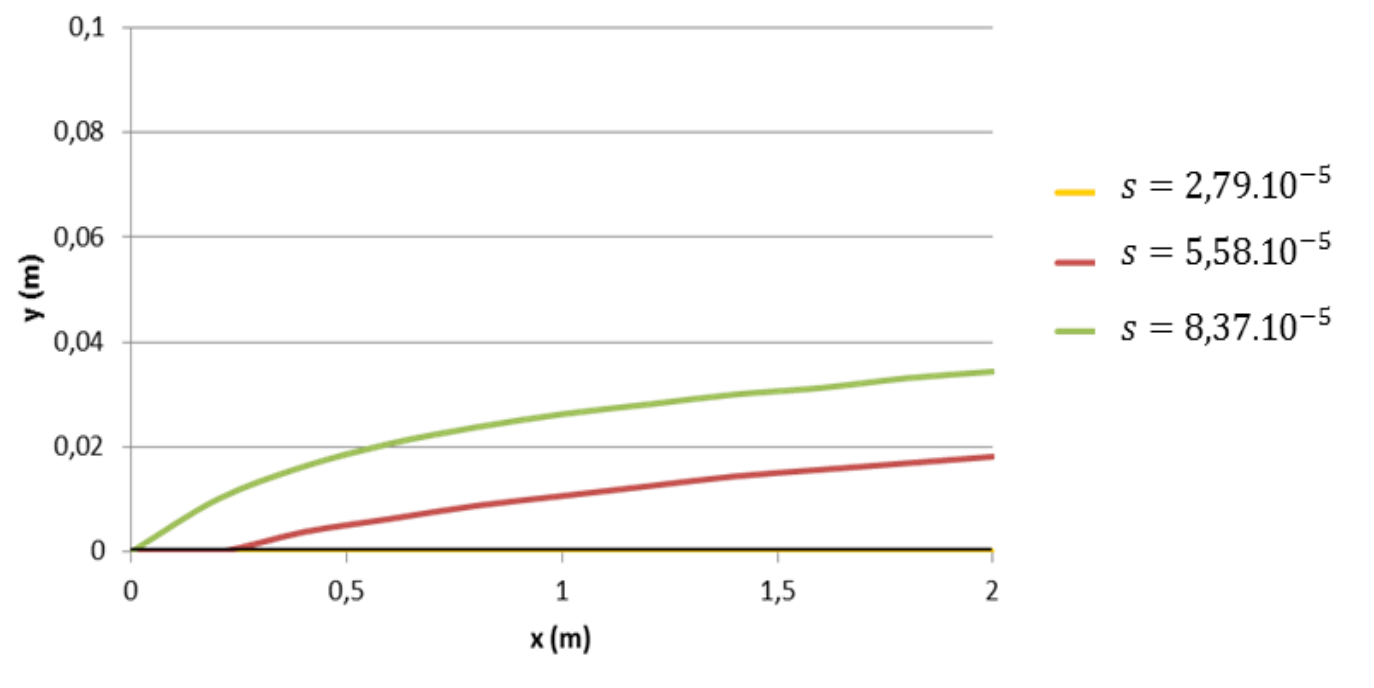

Figura 3-11 - Iso-linha de $\varnothing=0,5$, representando a superfície do leito de partículas ao longo do canal.

A Figura 3-12 apresenta o perfil de concentração de partículas na saída do canal para os diferentes casos. Observa-se que a concentração na base do canal sobe de pouco mais de 0,4 para 0,6, valor que se aproxima do valor crítico onde a viscosidade tende ao infinito. Observa-se, também, que em todos os casos existe um pico acima da metade do canal, que é devido ao efeito de migração influenciado pela frequência de migração entre as partículas, que as conduz para a região de menor cisalhamento, e devido ao efeito de migração influenciado pela variação espacial da viscosidade, que conduz as partículas de regiões de alta viscosidade para as regiões de baixa viscosidade.

A Figura 3-13 apresenta o perfil de velocidade na saída do canal. Através dos dados de simulação vimos que também houve uma diminuição de $Q^{*}$, de 
1,2-0,92-0,65. Ou seja, o aumento da densidade das partículas aumentou a deposição das mesmas, o que bloqueou uma maior parte na base do canal, diminuindo a vazão de fluxo.

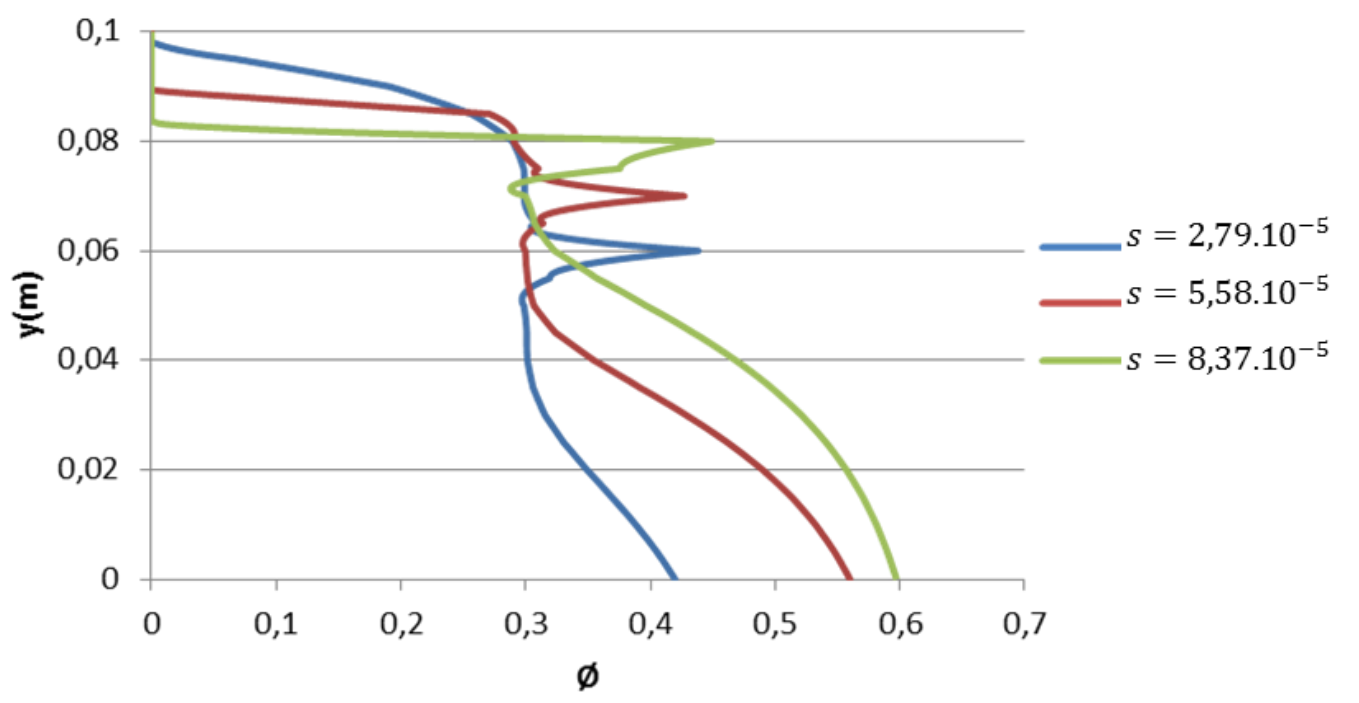

Figura 3-12 - Perfis de concentração na saída do canal para os casos variou-se a densidade das partículas, consequentemente $s$.

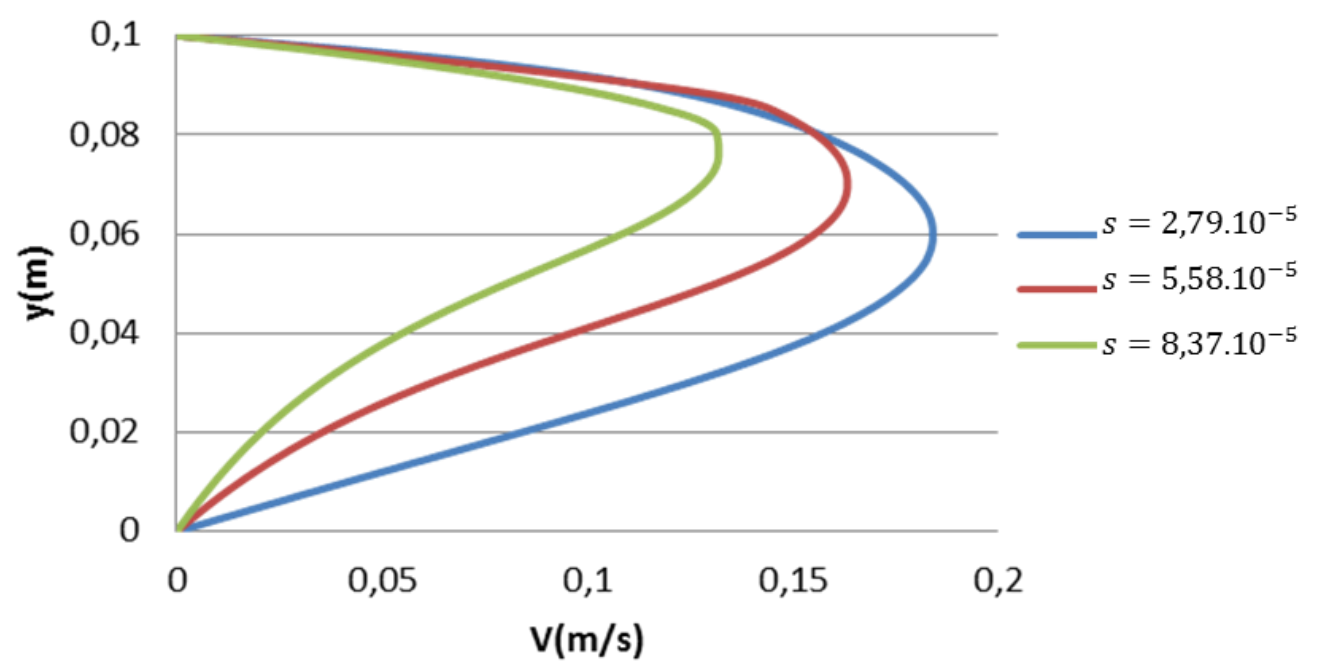

Figura 3-13 - Perfis de velocidade na saída do canal para os casos variou-se a densidade das partículas, consequentemente $s$.

Como era esperado, o aumento na densidade das partículas, sem alteração em nenhum dos demais parâmetros, provocou um aumento no valor 
do adimensional $s$ que, consequentemente, mostrou que 0 efeito da sedimentação teve uma maior influência dentro dos mecanismos de migração, provocando a formação de um leito de sedimentos mais denso, ao longo do canal.

\section{3. \\ Efeito da variação das constantes de proporcionalidade $K_{c}$ e $K_{\mu}$}

Após analisado a influência do efeito da gravidade nos mecanismos de migração, deseja-se, nesta seção, observar como cada um dos outros dois mecanismos influenciam na migração das partículas dentro do escoamento. Foram analisados dois casos diferentes, sendo que em cada um, uma das constantes de proporcionalidade foi mantida fixa enquanto a outra era variada.

No primeiro caso, manteve-se fixa a constante de proporcionalidade do mecanismo de migração devido à variação espacial da viscosidade, $K_{\mu}=0,18$, para que a constante de proporcionalidade do mecanismo de migração devido à frequência de interação entre as partículas, $K_{c}$, fosse avaliada. Nesses casos, $\Delta P^{*}=282,84$ e $s=8,37 \cdot 10^{-5}$. Os demais dados estão contidos na Tabela 3-6.

Tabela 3-6 - Dados das simulações para diferentes valores de $K_{c}$.

\begin{tabular}{|cccc|}
\hline Caso & $\mathrm{K}_{\mathrm{c}}$ & $\lambda$ & $\mathrm{Pe}$ \\
\hline$\lambda 1$ & 0,120 & 0,67 & $5.208,3$ \\
\hline$\lambda 2$ & 0,090 & 0,5 & $6.944,4$ \\
\hline$\lambda 3$ & 0,018 & 0,1 & $34.722,2$ \\
\hline
\end{tabular}

Foi possível observar, através da Figura 3-14, que esse efeito de migração não influencia significativamente o deslocamento das partículas, uma vez que para todas as três razões de $\lambda$ analisadas, todos os perfis de concentração na saída do canal apresentaram praticamente o mesmo comportamento, onde a concentração na base do canal gira em torno dos 0,6 e a região onde começa a fluir fluido limpo está em torno de 8 centímetros. Observa-se através da figura que a influência desse mecanismo se concentrou na região onde o $\dot{\gamma}$ é igual a zero, que é a região em $y \approx 0,08 m$, região em que a concentração das partículas aumenta com o aumento de $\mathrm{K}_{\mathrm{c}}$.

Esse não foi o mesmo comportamento observado no segundo caso, onde a constante de proporcionalidade do mecanismo de migração que leva em 
consideração a variação espacial da viscosidade, $K_{\mu}$, passou a variar. A constante $K_{c}$ foi mantida igual a 0,09 em todos os casos, onde $\Delta P^{*}=282,84$, $s=5,23 \cdot 10^{-5}$ e $P_{e}=6944,44$. Na Tabela 3-7 encontram-se os valores dos demais parâmetros utilizados.

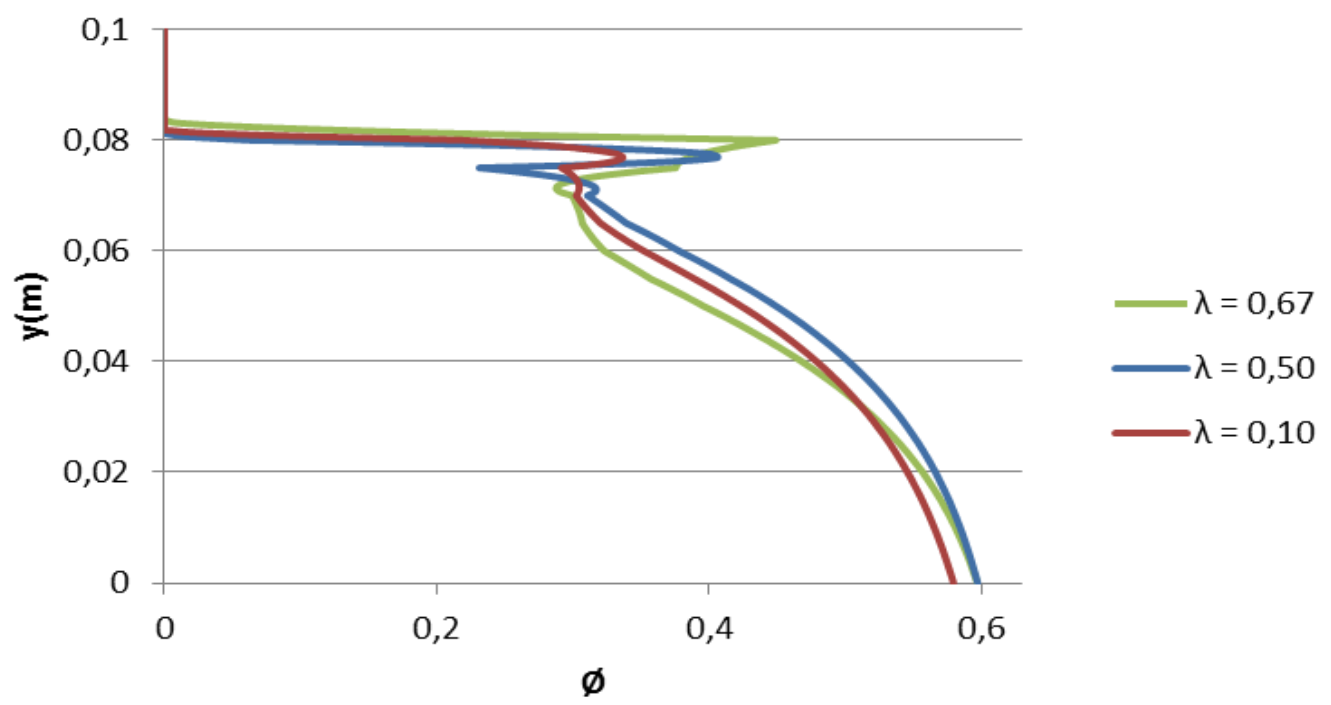

Figura 3-14 - Perfis de concentração na saída do canal para os casos em que o $\mathrm{K}_{\mathrm{c}}$ foi variado.

Tabela 3-7 - Dados das simulações para diferentes valores de $\mathbf{K}_{\mu}$.

\begin{tabular}{|ccc|}
\hline Caso & $K_{\mu}$ & $\lambda$ \\
\hline$\lambda 1$ & 0,90 & 0,1 \\
\hline$\lambda 2$ & 0,30 & 0,3 \\
\hline$\lambda 3$ & 0,18 & 0,5 \\
\hline$\lambda 4$ & 0,12 & 0,75 \\
\hline$\lambda 5$ & 0,10 & 0,9 \\
\hline
\end{tabular}

Através da Figura 3-15, observou-se que o efeito de migração devido à variação espacial da viscosidade é mais influente do que o efeito de migração devido à frequência de interação entre as partículas, pois ao variar o valor de $\lambda$ o perfil de concentração também sofreu alterações.

Sob esse efeito é possível concluir através dos perfis de concentração, que quando o valor de $K_{\mu}$ diminuiu, a concentração de partículas na base do canal aumentou, ou seja, quando os valores dessa constante são maiores, as 
partículas ao se chocarem tenderão a migrar das regiões de alta para baixa viscosidade distribuindo-se melhor ao longo da direção y. Diferentemente do que ocorre quando se diminui a influência desse efeito, assim ao se colidirem elas não terão força suficiente para migrar para as regiões de menores viscosidades se depositando com maior facilidade no fundo do canal, como mostra a Figura 3-15 para os casos $\lambda 3, \lambda 4$ e $\lambda 5$. Esses três últimos casos apresentaram o mesmo perfil de concentração.

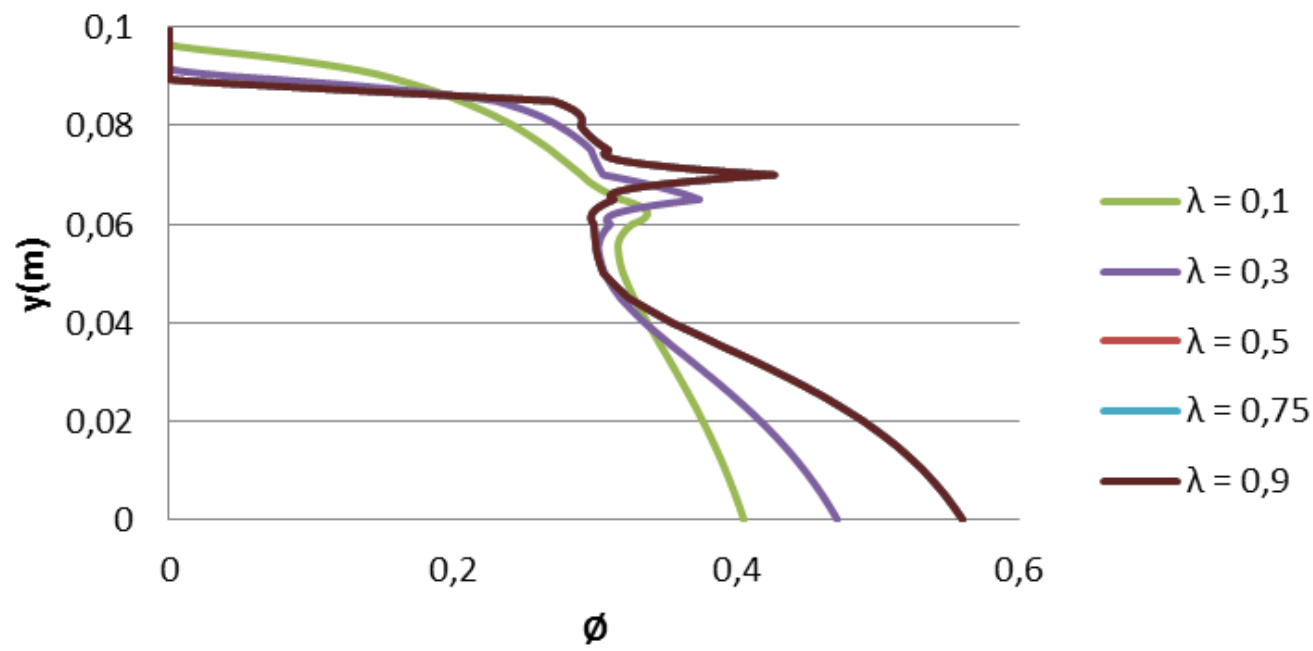

Figura 3-15 - Perfis de concentração na saída do canal para os casos em que o $\mathrm{K}_{\mu}$ foi variado.

Ainda foi realizada uma última análise nesta seção. O objetivo dos testes era observar qual seria o maior valor de $s$ permitido pelo programa antes de dar erro de convergência para casos com mesma razão de $\lambda$, porém para diferentes valores das constantes de proporcionalidade, e como seria o comportamento da concentração de partículas na saída do canal.

Foram realizados três testes, cujos dados estão contidos na Tabela 3-8, sendo $\lambda=0,667$ e $\Delta P^{*}=282,84$. Os três casos possuem valores de $\mathrm{K}_{\mathrm{c}}$ e $\mathrm{K}_{\mu}$ diferentes, porém a razão entre eles é mantida constante. Para cada caso foi possível chegar a um valor diferente de $\Delta \rho$ máximo, obtendo solução. O que se observou através da Figura 3-16, foi que para cada valor máximo de $\Delta \rho$ o perfil de concentração encontrado na saída do canal era igual aos demais. Ou seja, pode existir um limite de convergência para o qual todos os três mecanismos de migração influenciam da mesma forma o transporte dessas partículas, quando numa mesma razão de $\lambda$. 
Tabela 3-8 - Dados das simulações que testaram a limitação numérica do programa.

\begin{tabular}{|cccc|}
\hline Caso & $K_{c}$ & $K_{\mu}$ & $s$ \\
\hline$\lambda 1$ & 0,09 & 0,135 & $7,76 \cdot 10^{-5}$ \\
\hline$\lambda 2$ & 0,10 & 0,15 & $8,02 \cdot 10^{-5}$ \\
\hline$\lambda 3$ & 0,12 & 0,18 & $8,37.10^{-5}$ \\
\hline
\end{tabular}

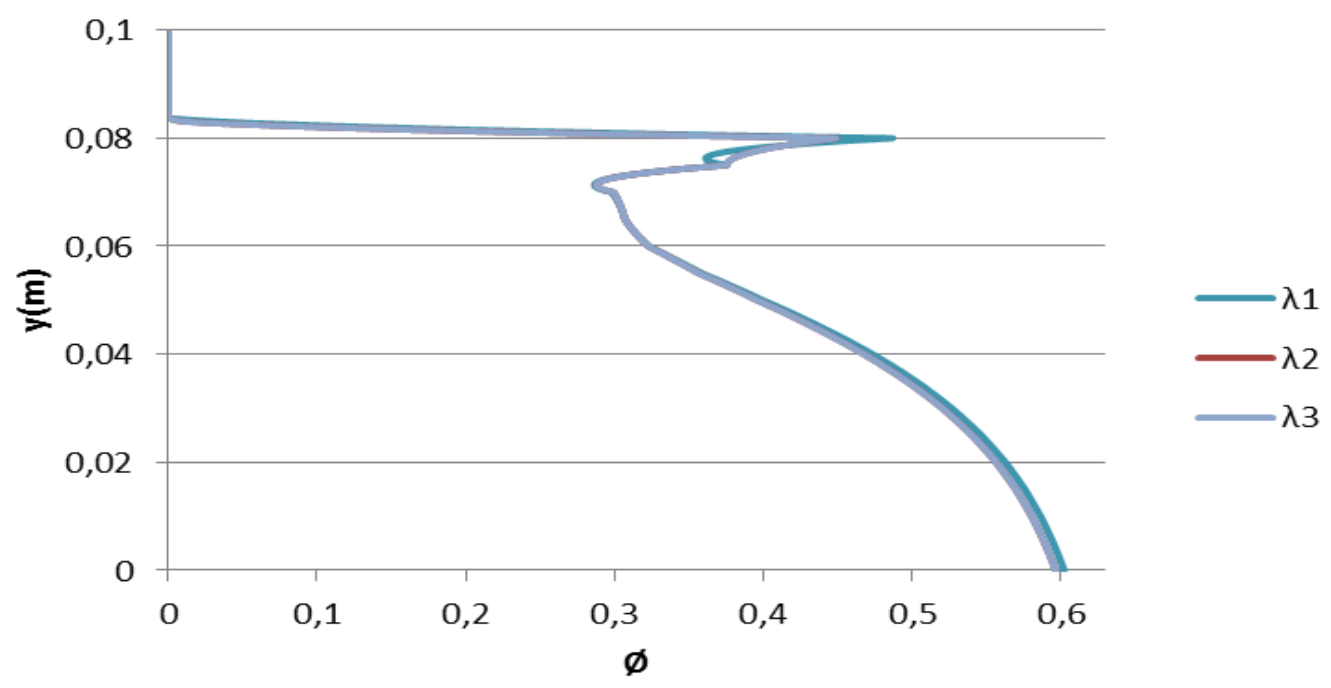

Figura 3-16 - Perfis de concentração para os casos em que a razão $\lambda$ foi mantida constante.

\section{4 . \\ Efeito da Variação da Pressão}

Nesta seção serão avaliados os resultados obtidos através da variação do diferencial de pressão imposta no canal. Poderá ser observado que essa variação modificará a vazão do escoamento, como mostra a Tabela 3-9. As demais propriedades nesses casos foram mantidas constantes e iguais a: $K_{c}=0,018 ; K_{\mu}=0,18$ e $\Delta \rho=1,1 \mathrm{~kg} / \mathrm{m}^{3}$. Os outros dois parâmetros adimensionais são $P e=34722,2$ e $\lambda=0,1$. O decréscimo do adimensional $s$ e o acréscimo nos valores de $\Delta P^{*}$, mostra que o efeito da sedimentação vai perdendo forças entre os mecanismos de migração e uma quantidade menor de partículas são depositadas no fundo do canal.

Para essas análises foi escolhido um caso em que tinha se formado um razoável leito de sedimentos e promoveu-se, então, um aumento no diferencial 
de pressão do canal, a fim de se avaliar como esse aumento da pressão influencia na deposição das partículas.

Tabela 3-9 - Dados das simulações que avaliam a variação do $\Delta P^{\star}$.

\begin{tabular}{|cccc|}
\hline Caso & $\Delta P^{*}$ & $\boldsymbol{s}$ & $\mathbf{Q}^{*}$ \\
\hline P1 & 282,84 & $9,59 \cdot 10^{-5}$ & 0,69 \\
\hline P2 & 308,22 & $8,08 \cdot 10^{-5}$ & 0,73 \\
\hline P3 & 331,66 & $6,98 \cdot 10^{-5}$ & 0,85 \\
\hline P4 & 353,55 & $6,14 \cdot 10^{-5}$ & 0,93 \\
\hline P5 & 393,70 & $4,95 \cdot 10^{-5}$ & 1,03 \\
\hline P6 & 412,31 & $4,51 \cdot 10^{-5}$ & 1,06 \\
\hline
\end{tabular}

Observa-se através da Figura 3-17(a) um leito sedimentado de partículas ocupando quase $4 \mathrm{~cm}$ da base do canal. À medida que se incrementou 0 diferencial de pressão imposta ao canal, aumentou-se o efeito do mecanismo de migração devido à sedimentação e a quantidade de partículas que era depositada no fundo do canal ia diminuindo, ao passo de que no último caso nenhuma partícula foi depositada, todas estavam escoando juntamente com a parte fluida.

A evolução na limpeza do canal para os diferentes valores de $\Delta P$ está ilustrada na Figura 3-18. Esta figura mostra a altura do leito de sedimentos para cada caso. É importante destacar que o caso $P 6$ a concentração ao longo do canal não excede o valor de 0,50 , ou seja, todas as partículas estão escoando juntamente com a fase líquida. Ainda nesta figura, foram plotadas duas equações de potência para os casos de maiores altura do leito, a fim de buscar uma possível correlação que descreva o crescimento desse leito ao longo do canal. Essa correlação foi feita longe da entrada do canal. Através das duas equações podemos destacar que a altura do leito será proporcional a uma constante, que estará correlacionada à vazão do escoamento, e a aproximadamente $x^{0,5}$, sendo assim:

$$
h=\text { const. } x^{0,5}
$$

Vale ressaltar que, essa relação só é verdadeira para a região de desenvolvimento do leito, pois como será visto ao final deste capítulo chegará um ponto em que este crescimento se estabiliza. 


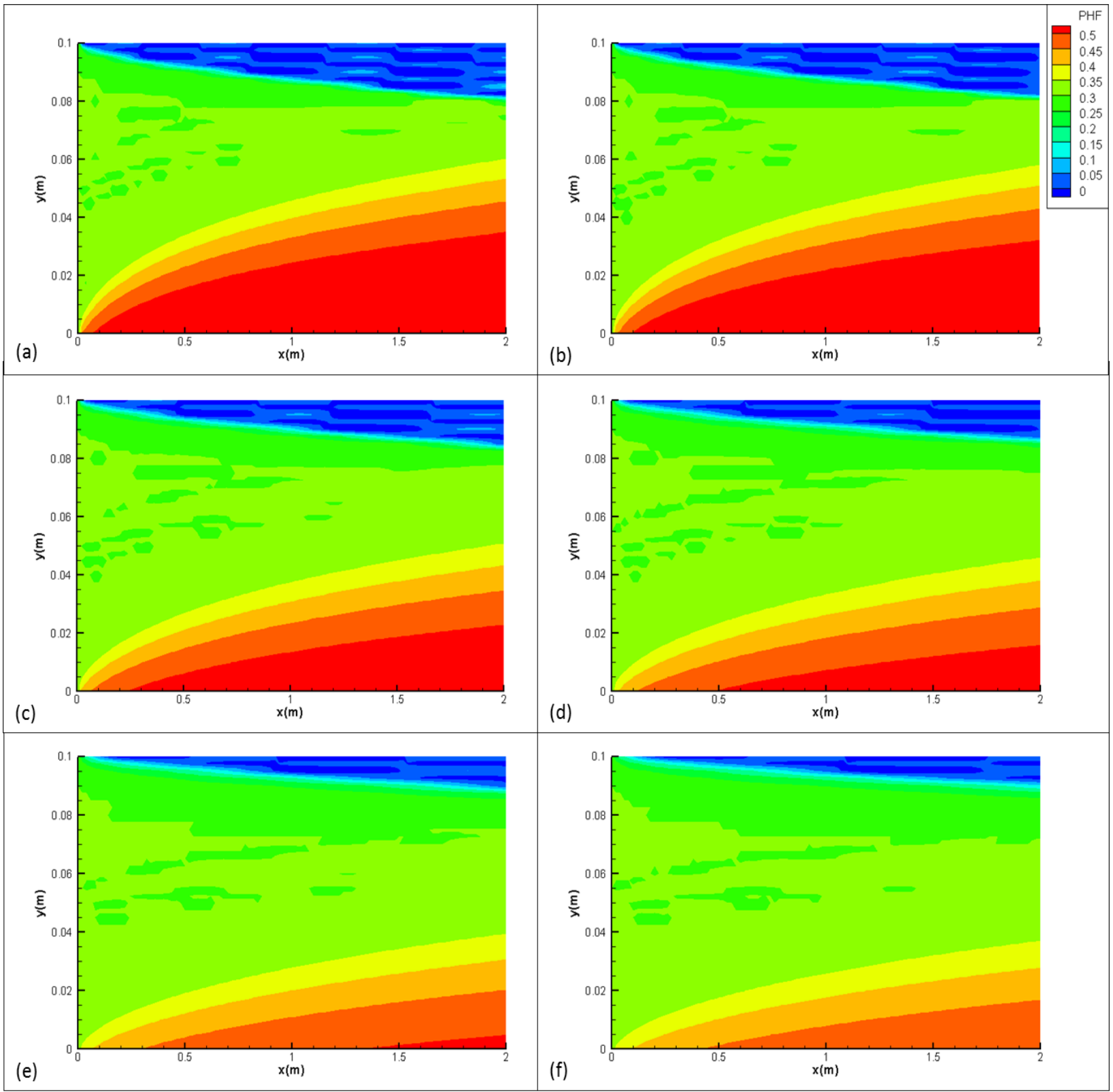

Figura 3-17 - Perfis de concentração ao longo do canal para os casos cujo $\Delta P^{*}$ vale: (a) 282,84, (b) 308,22, (c) 331,66, (d) 353,55, (e) 393,70 e (f) 412,31. 


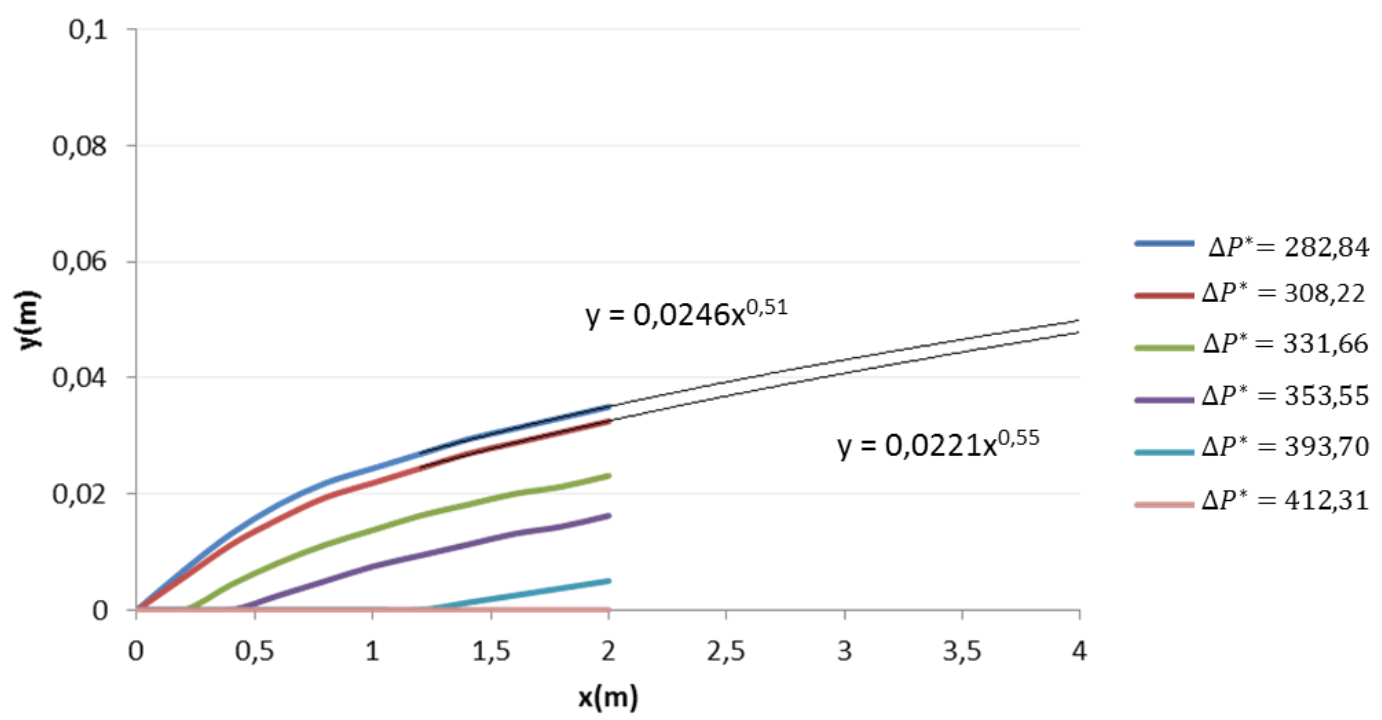

Figura 3-18 - Perfis que mostram a evolução da formação do leito de sedimentos $(\varnothing \geq 0,5)$ ao longo do canal.

A Figura 3-19 mostra o perfil de velocidade na saída do canal. Observa-se que o aumento de $\Delta P^{*}$ promove também um aumento na velocidade, consequentemente, o aumento na vazão de escoamento do canal.

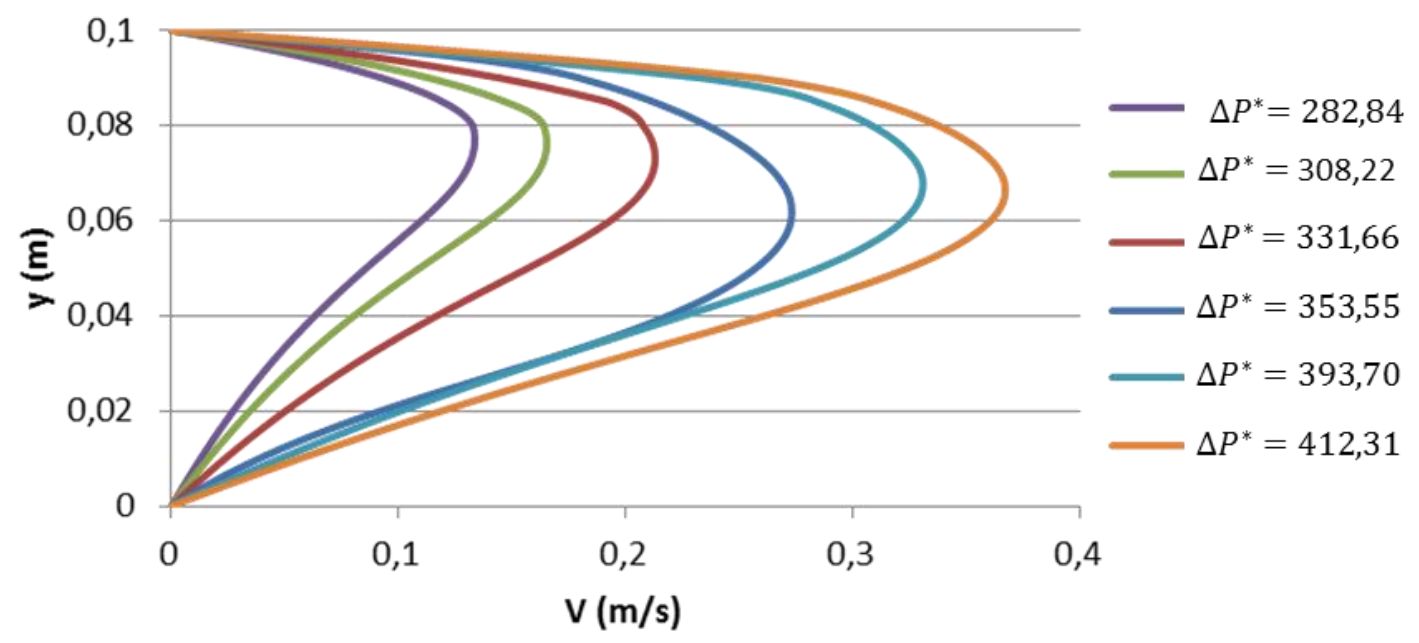

Figura 3-19 - Perfis de velocidade na saída do canal para os casos em que $\Delta \boldsymbol{P}^{\star}$ era variado.

Já a Figura 3-20 apresenta o perfil da concentração de partículas na saída do canal. Observa-se que, com o aumento do diferencial de pressão imposto, a espessura da camada de fluido limpo no topo do canal diminui, consequentemente a concentração na base do canal também diminui. 


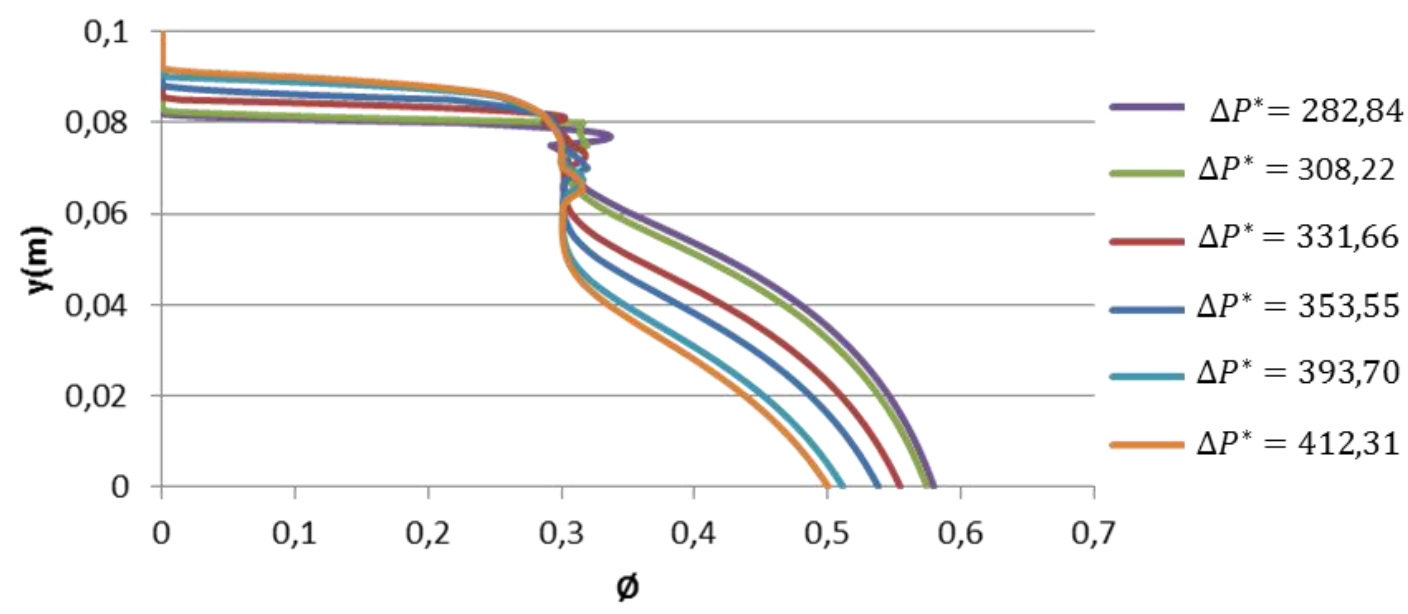

Figura 3-20 - Perfis de concentração na saída do canal para os casos em que $\Delta \boldsymbol{P}^{\star}$ era variado.

Esse comportamento mostra que a sedimentação das partículas diminui e elas são melhor distribuídas ao longo do canal, destacando-se o último caso em que se observa que a região no centro do canal, onde a concentração é igual à concentração média de entrada, aumenta.

Para melhor observar o efeito da sedimentação das partículas seria necessário aumentar ainda mais a densidade das mesmas, para isso foi preciso aumentar também a diferença de pressão imposta ao canal. Assim, de forma intercalada foram sendo aumentados $0 \Delta P$ e $\circ \Delta \rho$, o que permitiu observar o desenvolvimento do leito de partículas já para um canal de 2 metros de comprimento.

O $\Delta \rho$ em que, primeiramente, se observou esse comportamento foi de $25,3 \mathrm{~kg} / \mathrm{m}^{3}$, sendo em seguida promovido um aumento no $\Delta P$, como mostra a Figura 3-21. Esta figura mostra que, para o caso em que $\Delta P=1700 \mathrm{~Pa}$ (a), as partículas se depositam no fundo do canal e formam o leito estacionário quase que totalmente desenvolvido. Como mencionado anteriormente, em concentrações acima de $\varnothing=0,5$ o leito está praticamente imóvel e na figura observa-se que, nos últimos $50 \mathrm{~cm}$ do canal, praticamente não ocorre variação na altura do leito. E o segundo perfil (b), com $\Delta P=3900 P a$, mostra que esse aumento da pressão imposta foi suficiente para não permitir que as partículas se depositassem no fundo do canal, permanecendo em suspensão. 


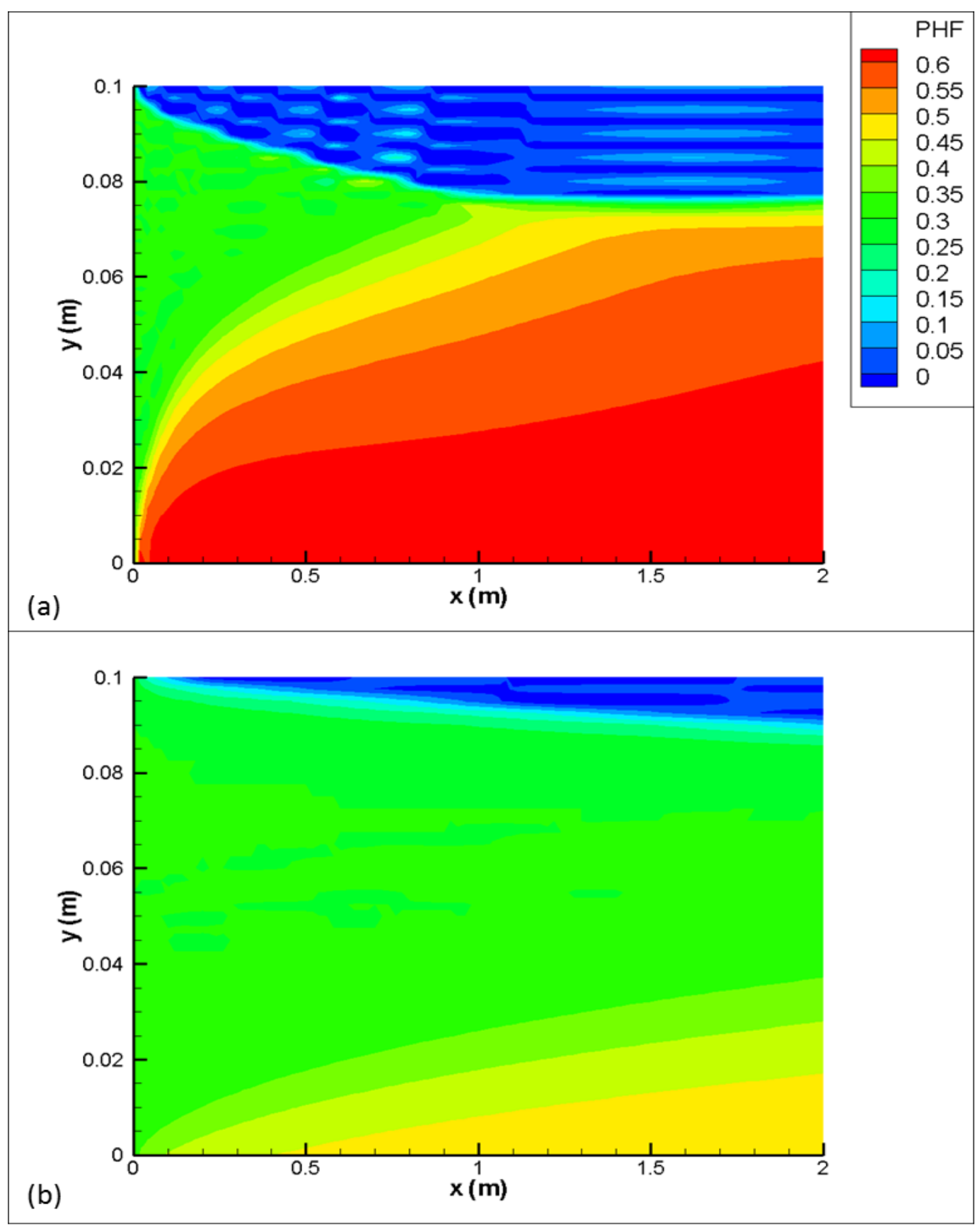

Figura 3-21 - Perfis de concentração ao longo do canal para um $\Delta \rho=25,3 \mathrm{~kg} / \mathrm{m}^{3}$ e um $\Delta P^{\star}$ diferente para os dois casos, sendo (a) 1303,84 e (b)1974,84. 
Ao analisar de forma conjunta os perfis de concentração e de velocidade do caso (a) da Figura 3-21, observa-se claramente que a velocidade das partículas dentro do leito é muito menor do que a região do topo do canal, por onde flui apenas a parte líquida, como mostra a Figura 3-22. Na região do topo do canal o perfil se assemelha a um parabólico.

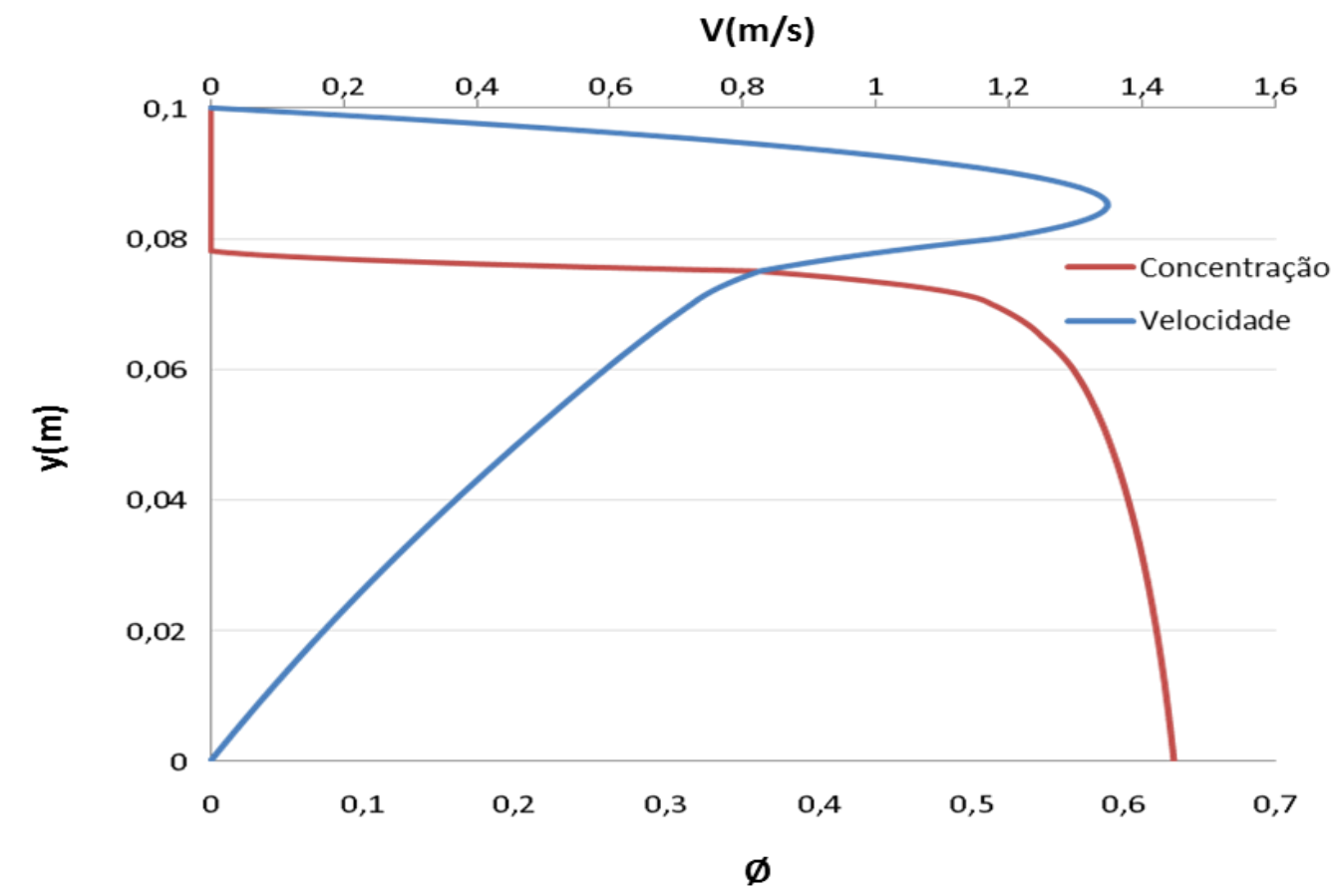

Figura 3-22 - Perfis de concentração e velocidade, para $\Delta \rho=25,3 \mathrm{~kg} / \mathrm{m}^{3}$ e $\Delta P^{\star}=1303,84$.

Com o intuito de verificar uma consistência nesse comportamento promoveu-se o incremento hora do diferencial de pressão imposto, hora da densidade das partículas, como mostra a Tabela 3-10, sendo os outros adimensionais iguais para os 5 casos, $P_{e}=34722,2$ e $\lambda=0,1$. O comportamento da concentração de partículas na saída do canal é apresentado na Figura 3-23. Observa-se que não importa o valor do diferencial de pressão imposto, para valores de $\Delta P^{*} \geq 1303,84$ o perfil de concentração obtido será sempre igual. $O$ mesmo acontece quando o objetivo é não permitir que as partículas se depositem e formem o leito, onde o $\Delta P^{*}$ necessário irá gerar o mesmo perfil de concentração na saída do canal. 
Tabela 3-10 - Dados das simulações para variados valores de $\Delta P^{\star}$ e $\Delta \rho$.

\begin{tabular}{|ccccc|}
\hline Caso & $\Delta \boldsymbol{\rho}\left(\mathbf{K g} / \mathbf{m}^{\mathbf{3}}\right)$ & $\Delta P^{*}$ & $\boldsymbol{s}$ & $\mathbf{Q}^{*}$ \\
\hline 1 & 25,3 & 1303,84 & $1,04 \mathrm{E}-04$ & 0,24 \\
\hline 2 & 25,3 & 1974,84 & $4,53 \mathrm{E}-05$ & 1,06 \\
\hline 3 & 57,95 & 1974,84 & $1,04 \mathrm{E}-04$ & 0,028 \\
\hline 4 & 57,95 & 2990,82 & $4,52 \mathrm{E}-05$ & 1,06 \\
\hline 5 & 132,65 & 2990,82 & $1,03 \mathrm{E}-04$ & 0,024 \\
\hline
\end{tabular}

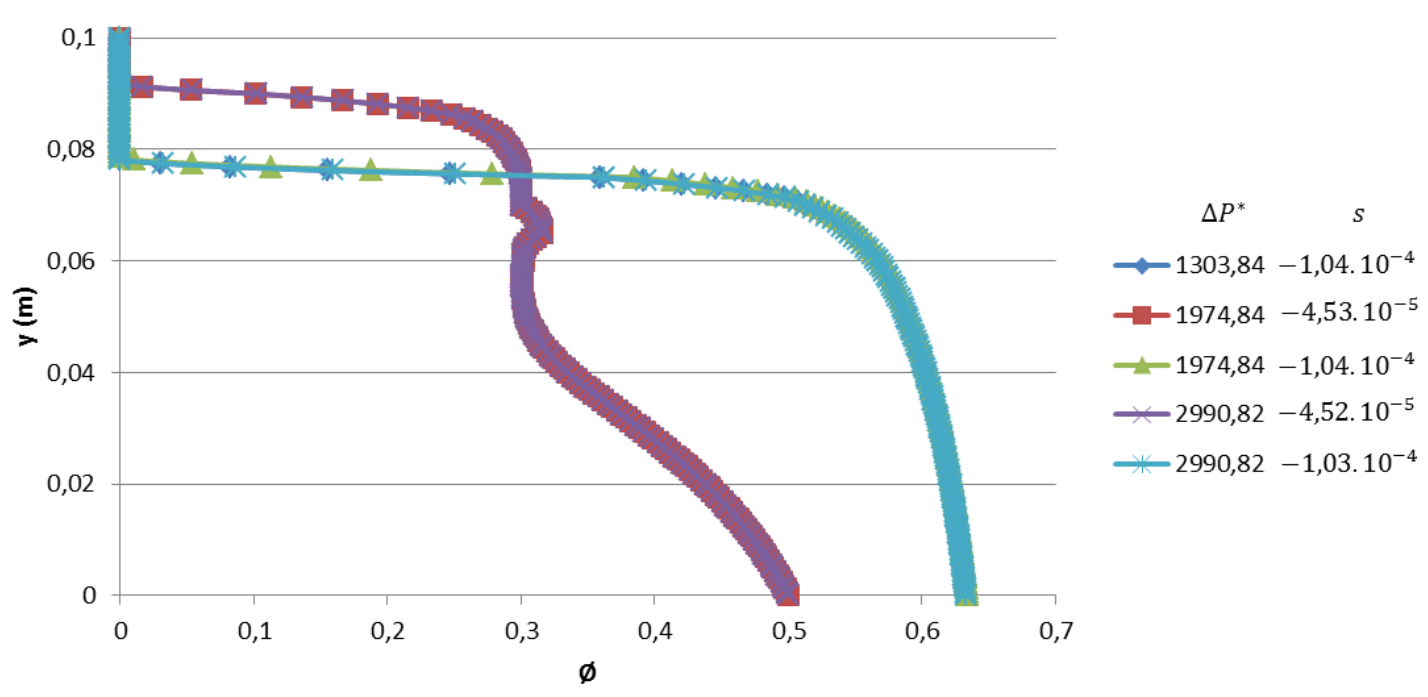

Figura 3-23 - Perfis de concentração na saída do canal para os diferentes valores de $\Delta P^{\star}$ e $s$.

A Figura 3-24 apresenta os perfis de velocidade para esses casos. Fica claro nos casos 1, 3 e 5, onde observa-se a formação do leito de partículas, que na região de maior concentração as partículas estão praticamente paradas, visto que possuem uma velocidade muito baixa, diferentemente do topo do canal que não está obstruído e a fase líquida escoa livremente com maiores velocidades. Já para os casos $2 e 4$, que são os casos onde a pressão imposta foi incrementada para evitar a formação do leito, observa-se uma maior homogeneidade do perfil, com um comportamento mais parecido a um perfil parabólico, mostrando que todas as partículas estão dentro do escoamento. 


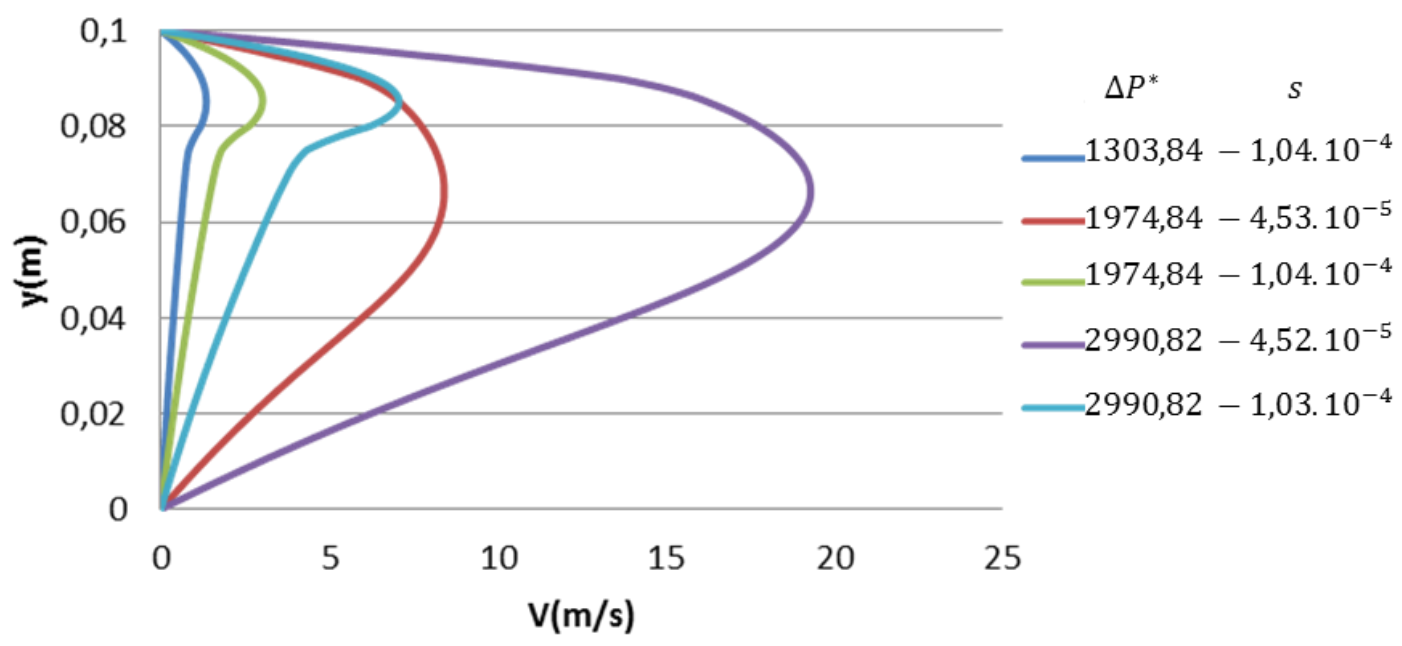

Figura 3-24 - Perfis de velocidade na saída do canal para os diferentes valores de $\Delta \boldsymbol{P}^{\star}$ e $s$.

Assim, analisando os valores dos adimensionais desses casos apresentados na Tabela 3-10 é importante destacar o que acontece com o parâmetro $s$. Observa-se que os casos 1,3 e 5, em que se obtém o perfil máximo de concentração, possuem o mesmo valor desse adimensional, $s \approx 10^{-4}$. Da mesma forma que acontece para os casos $2 e 4$, nos quais não existe formação de leito, onde $s \approx 4,5 \cdot 10^{-5}$. Ou seja, conclui-se que a altura do leito está diretamente relacionada a esse parâmetro adimensional.

Para ilustrar essa relação utilizou-se a Figura 3-25. Este diagrama apresenta o comportamento tanto do crescimento da altura do leito, linha vermelha, quanto da região do topo por onde flui apenas a fase líquida, linha azul. A região do centro entre essas duas linhas compreende a faixa de concentração entre $0<\emptyset<0,5$, ou seja, a região do canal por onde as partículas estão suspensas e, portanto, carreadas pela fase líquida. Através de uma extrapolação das curvas é possível observar que chegará um momento em que elas se cruzarão atingindo o total desenvolvimento do leito, ou seja, a partir desses valores de $s$ para o canal com 2 metros de comprimento o leito de partículas já atingirá o estado desenvolvido. 
Resultados

66

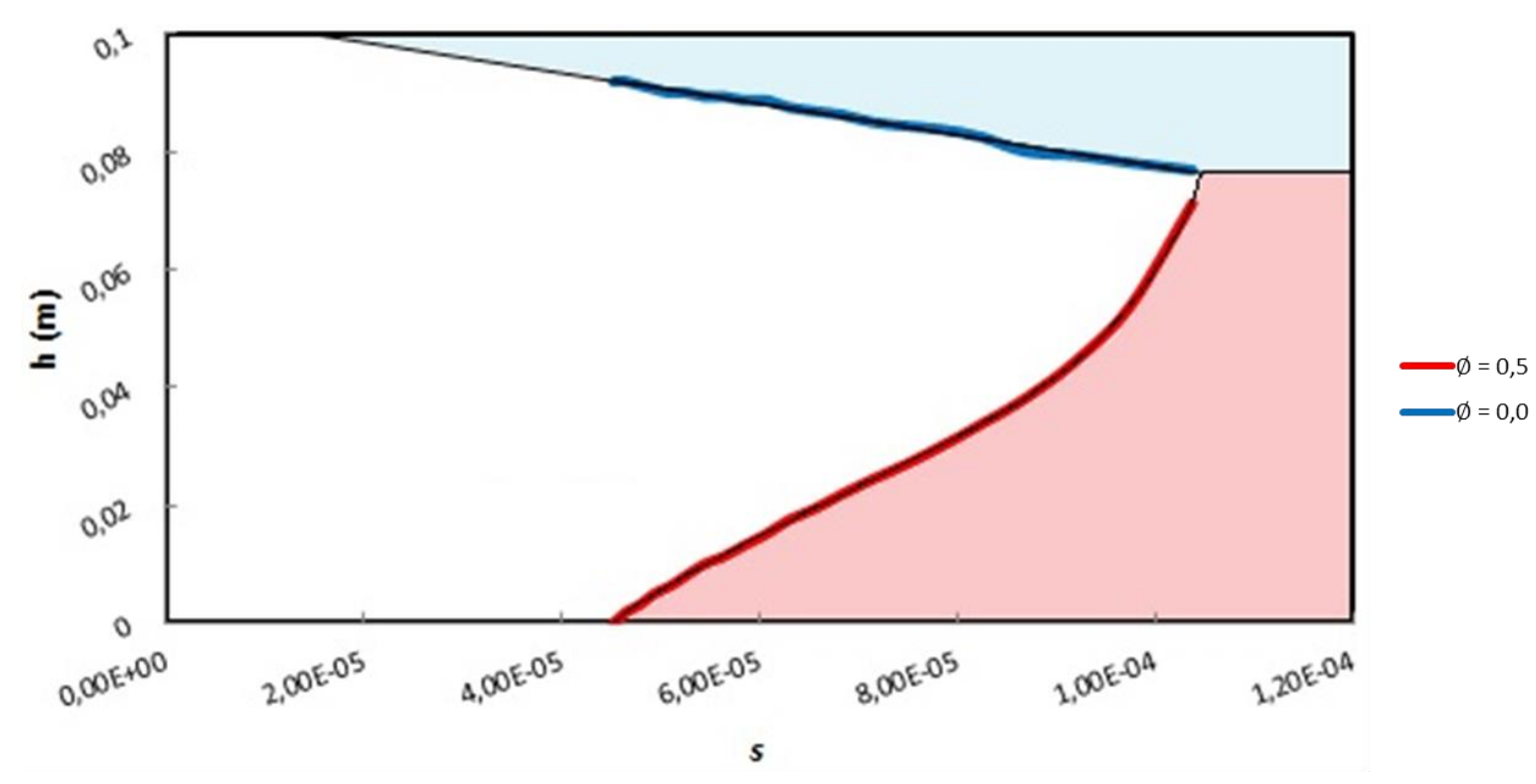

Figura 3-25 - Diagrama representando a relação entre a altura do leito e o parâmetro adimensional $s$.

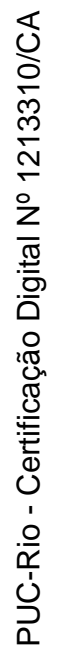




\section{4 \\ Comentários Finais/Sugestões}

Problemas com o transporte de cascalhos são frequentes durante a perfuração de poços de petróleo. Sabe-se que, quando esta operação não é bem sucedida ocorre uma série de problemas, que podem, até mesmo em casos extremos, promover a perda do poço. Dessa forma, ao longo dos anos se intensifica o estudo sobre este tema, a fim de obter um melhor entendimento e descrever de forma mais precisa este processo, evitando tais problemas.

Com este objetivo, estudou-se o escoamento laminar bidimensional de suspensões de partículas sólidas devido a um gradiente de pressão imposta entre duas placas paralelas. Sabe-se que, no cenário real de um poço de petróleo o escoamento acontece no espaço anular, com geometria cilíndrica tridimensional, porém, optou-se por uma representação simplificada do processo, sem perder as características reais do escoamento, devido a limitações numéricas.

Este estudo propôs a caracterização do escoamento avaliando a migração das partículas sólidas em relação a três mecanismos diferentes, sendo eles devido aos gradientes de taxa de cisalhamento e de viscosidade e, à diferença de densidade entre as partículas e a fase líquida. Além de descrever o perfil do leito de partículas ao longo do canal e a relação vazão-diferença de pressão para diferentes condições de escoamento.

Dentre os mecanismos de migração observou-se que enquanto o efeito de migração devido à resistência ao movimento, ou seja, devido à diferença de densidade entre as partículas sólidas e a fase líquida, empurra as partículas para o fundo do canal, os outros dois mecanismos de migração devido aos gradientes de viscosidade e de taxa de cisalhamento empurram as partículas da base para o topo do canal.

Observou-se que para partículas mais densas o efeito de migração mais significativo foi o de sedimentação, visto que elas se depositaram mais rapidamente no fundo do canal, formando leitos mais espessos, ou seja, para essas partículas o efeito da gravidade foi mais intenso.

Quando analisado os mecanismos de difusão por gradiente de taxa de cisalhamento e viscosidade, pode-se concluir que eles são responsáveis pela 
ressuspensão das partículas sólidas, sendo que o mecanismo de migração devido ao gradiente de viscosidade é o mais influente entre os dois. Observando ainda que, os coeficientes de difusão influenciam fortemente a estrutura do leito e do escoamento.

O diferencial de pressão imposta no canal é responsável pela força que evita que as partículas se depositem e formem o leito, mantendo todas em suspensão. Observou-se que, para partículas de mesma densidade quanto maior for o $\Delta P$ menos elas se depositarão no fundo do canal, consequentemente menor será o leito formado, chegando até mesmo em condições em que todas as partículas continuam em suspensão sendo carreadas pela fase líquida. Além disso, foi possível determinar uma relação direta entre a altura do leito formado e o parâmetro adimensional $s$, que é influenciado por esse diferencial de pressão e pela densidade das partículas, observando que para maiores valores de $s$ maior era a altura do leito de partículas formado.

A seguir são apresentadas algumas sugestões para melhoria deste estudo, a fim de buscar descrever de forma mais precisa esse processo:

- recomenda-se o uso de uma geometria cilíndrica tridimensional para se assemelhar ao cenário real do problema, além de analisar também o escoamento turbulento;

- aumentar o comprimento do canal, realizando uma melhoria no código computacional, para evitar problemas de convergência;

- realizar uma análise mais detalhada de variáveis que foram mantidas constantes nesse estudo, tais como: a altura do canal, o raio das partículas, a concentração média de entrada das partículas, a viscosidade do fluido considerando a dependente da taxa de cisalhamento, dentre outras;

- analisar modelos que descrevem a viscosidade da suspensão propostos por outros autores;

- $\quad$ por fim, recomenda-se um estudo experimental desse processo, a fim de validar os resultados obtidos permitindo uma melhor compreensão do escoamento de partículas ao longo de um canal. 


\section{Referência Bibliográfica}

ACRIVOS, A. et al. Shear-Induced Resuspension in a Couette Device. International Journal of Multiphase Flow. Vol. 19, No. 5, p. 797-802, 1993.

ARAUJO, S. B. D. Slot Coating Particle Suspension. MsC thesis, Pontifícia Universidade Católica do Rio de Janeiro. Rio de Janeiro, RJ, Brasil, 2014.

CARVALHO, M. S. Deformable Roll Coating in Rigid and Deformable Gaps. Phd thesis, University of Minnesota. Minneapolis, MN, USA, 1996.

CHAPMAN, B. K.; LEIGHTON, D. T. Dynamic Viscous Resuspension. International Journal of Multiphase Flow. Vol. 17, No. 4, p. 469-483, 1991.

COSTA, S. S.; FONTOURA, S. A. B. D. Aspectos Importantes de Limpeza de Poços de Petróleo. $3^{\circ}$ Congresso Brasileiro de P\&D em Petróleo e Gás. Salvador, BA, 2005.

GADALA-MARIA, F. A. The rheology of concentrated suspensions. Thesis, Stanford University, 1979.

KRIEGER, I. M. Rheology of Monodispersed Latices. Advences in Colloid and Interface Science. Vol. 3, No. 2, p. 111-136, 1972.

LALLI, F.; MASCIO, A. D. A Numerical Model for Fluid-Particle Flows. International Journal of Offshore and Polar Engineering. Vol. 7, No. 2, 1997.

LEIGHTON, D.; ACRIVOS, A. Viscous Resuspension. Chemical Engineering Science. Vol. 41, No. 6, p. 1377-1384, 1986.

LEIGHTON, D.; ACRIVOS, A. Measurements of the shear induced coefficient of self-diffusion. Journal of Fluid Mech. Vol. 177, p. 109-131, 1987a.

LEIGHTON, D.; ACRIVOS, A. The Shear-Induced Migration of Particles in Concentrated Suspensions. Journal of Fluid Mech. Vol. 181, p. 415-439, 1987b. 
LI, Y. et al. Numerical Modelling of Cuttings Transport in Horizontal Wells Using Conventional Drilling Fluids. Journal of Canadian Petroleum Technology. Vol. 46, No. 7, 2007.

MISKIN, I. et al. The Viscous Resusension of Particles in an Inclined Rectangular Fracture. International Journal of Multiphase Flow. Vol. 22, No. 2, p. 403-415, 1996a.

MISKIN, I. et al. Steady Suspension Flows into Two-Dimensional Horizontal and Inclined Channels. International Journal of Multiphase Flow. Vol. 22, No. 6, p. 1223-1246, 1996b.

PANTON, R. L. Incompressible Flow. $3^{a}$. ed. Hoboken, New Jersey: John Wiley \& Sons, 2005, $821 p$.

PHILLIPS, R. J. et al. A constitutive equation for concentrated suspensions that accounts for shearinduced particle migration. Physics of Fluids A. Vol. 4, No. 1, p. 30-40, 1992.

RAI, M. M.; MOIN, P. Direct Simulations of Turbulent Flow Using FinitDifference Schemes. J Comp Physics, 1991.

ROMERO, O. J. Limite da Vazão Mínima do Processo de Revestimento por Extrusão de Soluções Poliméricas. $\mathrm{PhD}$ thesis, Pontifícia Universidade Católica do Rio de Janeiro, Rio de Janeiro, RJ, Brasil, 2003.

SANI, R. L. E. A. The cause and cure (?) of the spurious pressures generated by certain FEM solutions of the incompressible Navier Stokes equations: Part 1, 2. International Journal for Numerical Methods in Fluid. Vol. 1, No. 1, p. 17-43; No. 2, pp. 171-204, 1981.

SCHAFLINGER, U. et al. Viscous Resuspension of a Sediment within a Laminar and Stratified Flow. International Journal of Multiphase Flow. Vol. 16, No. 4, p. 567-578, 1990.

SILVA, L. D. V. Analysis of Slot Coating Process of Particle Suspensions. MsC thesis, Pontifícia Universidade Católica do Rio de Janeiro. Rio de Janeiro, RJ, Brasil, 2013. 
ZHANG, K. et al. Stability in a Two-Dimensional Hagen-Poiseuille Resuspension Flow. International Journal of Multiphase Flow. Vol. 18, No. 1, p. 51-63, 1992.

ZHANG, K.; ACRIVOS, A. Viscous Resuspension in Fully Developed Laminar Pipe Flows. International Journal of Multiphase Flow, Vol. 20, No. 3, p. 579-591, 1994. 